\title{
STRENGTHENING OF STEEL PLATES SUBJECTED TO UNIAXIAL COMPRESSION USING SMALL-DIAMETER CFRP STRANDS
}

\author{
Hamid Kazem¹, Lucas Guaderrama ${ }^{1}$, Hatem Selim², Sami Rizkalla ${ }^{4}$, Akira Kobayashi ${ }^{3}$ \\ ${ }^{1}$ Department of Civil, Construction and Environmental Engineering, North Carolina State University, \\ Raleigh, USA \\ ${ }^{2}$ Associate Professor of Structural Engineering, Helwan University, Egypt \\ ${ }^{3}$ Nippon Steel \& Sumikin Material Co., Ltd, Composites Company, Japan \\ ${ }^{*}$ Corresponding author. E-mail addresses: sami_rizkalla@ncsu.edu, \\ Phone: 919.513.1733, Fax: 919.513.1765
}

\section{ABSTRACT:}

This paper presents the results of a study that was carried out to investigate the use of small-diameter CFRP strands for strengthening steel plates subjected to uniaxial compression. This study is part of a comprehensive research program to evaluate the use of the small-diameter CFRP strands for shear strengthening of steel girders. The research in this paper was undertaken to examine the bond characteristics of the proposed material which is expected to eliminate the debonding failure observed for CFRP laminates strengthening system and to resist the compressive stresses induced in high shear zones. The small-diameter CFRP strands are stitched together with a gap between the strands to allow each strand to be completely covered by the adhesive material. The effectiveness of the strengthening system was investigated by varying various parameters believed to affect the overall behavior including the slenderness ratio of the steel plates as well as mechanical properties and reinforcement ratios of the CFRP strands. Strengthened plates exhibited higher buckling capacity in comparison to similar plates without CFRP strands. In addition, the small-diameter CFRP strands did not show any signs of debonding at large lateral deformation associated with elastic buckling.

Keywords: Carbon fiber, Buckling, Debonding, Steel 


\section{Introduction}

2 Use of Fiber Reinforced Polymer (FRP) materials for strengthening of concrete structures and bridges

3 has gained wide acceptance worldwide, due to its appealing benefits [1]. There is also a growing demand

4 for strengthening steel structures and bridges due to increase of load demand and/or possible reduction

5 of the load-carrying capacity due to deterioration. Traditional strengthening techniques for steel structures

6 include welding or bolting steel plates or sections to the existing structure. However, increase of dead

7 load, cost of construction, labor intensity, and interruptions to traffic flow for bridges are significant

8 downsides of the current strengthening techniques [2]. Therefore, the need for alternative strengthening

9 materials and techniques is evident.

10 Use of Fiber-Reinforced Polymer (FRP) strengthening systems for steel structures have revealed many

11 advantages including high strength-to-weight ratios, corrosion resistance, and ease of construction in

12 comparison to the use of steel strengthening materials [3]. Use of externally bonded FRP materials for

13 strengthening steel structures did not progress similar to its use for concrete structures due to the low

14 elastic modulus of FRP relative to steel. However, the recent innovative use of prestressed CFRP plates

15 for strengthening steel structures is proven to be effective [4]. The recent production of high-modulus

16 Carbon FRP (CFRP) laminates with an elastic modulus similar to or higher than that of steel offers a

17 promising alternative for externally bonded strengthening system for steel structures $[5,6]$.

18 Researches have explored the use of externally bonded, high-modulus CFRP materials for flexural

19 strengthening of steel members and have shown significant increase in flexural capacity and stiffness [4,

$207,8,9,10$ and 11]. Nevertheless, to increase the total load-carrying capacity of the strengthened

21 member, the shear capacity should also be increased along with its flexural capacity.

22 The shear strength of steel beams is controlled by the capacity of the web plate. Failure of the web plate

23 due to elastic buckling or yielding of the material depends on the slenderness ratio of the web. The elastic

24 buckling of slender web plates is directly related to level of the principal compressive stresses induced at

25 the high shear zone(s) of the beam. Strengthening of web plates using CFRP materials has the potential

26 to reduce the stress level in the web, and consequently increase the shear-carrying capacity of the web. 
In order to evaluate the efficiency of CFRP materials for enhancing the shear strength of steel beams,

2 their behavior in resisting the principal compressive stresses and their ability to undergo large

3 deformations associated with buckling should be determined. Several studies have been reported on the

4 use of CFRP laminates to increase the compressive resistance of steel members. Shaat \& Fam (2006)

5 [12] investigated the behavior of axially loaded short and long columns wrapped with both longitudinal

6 and transverse CFRP sheets. Test results showed that debonding of CFRP sheets occurred for both

7 short and long columns. Short-column specimens experienced debonding between steel and CFRP

8 layers when local buckling occurred. Failure of strengthened long-column specimens was due to local

9 buckling associated with combined debonding and crushing of the CFRP sheets. The web-crippling

10 behavior of rectangular hollow sections (RHS) strengthened with CFRP sheets and plates was

11 investigated by Zhao et al. (2006) [13]. Results indicated that the web crippling capacity was significantly

12 increased by using CFRP sheets and CFRP plates strengthening systems, especially for those with large

13 web depth-to-thickness ratio. Shaat \& Fam (2009) [14] presented the results of an experimental

14 investigation into the behavior of slender steel columns strengthened with high-modulus CFRP plates

15 under uniaxial compression loads. CFRP failure was observed to be due to debonding or crushing of the

16 material prior to or after overall buckling of the column, depending on the column slenderness ratio.

17 Harries et al. (2009) [15] performed experimental research on improving buckling behavior of short and

18 long columns using FRP materials which the failure was due to debonding at the post-peak behavior.

19 The web-buckling of light-steel beams strengthened with FRP systems was explored by Zhao \& Al-

20 Mahaidi (2009) [16]. Test results demonstrated significant increase in the web-buckling capacity,

21 especially for specimens with high depth-to-thickness ratios. Aguilera \& Fam (2013) [17] studied the

22 effectiveness of externally bonded FRP plates to strengthen hollow steel section T-Joints. The

23 effectiveness of the strengthened system was more pronounced with higher slenderness ratio.

24 The proposed small-diameter CFRP strands shown in Figure 1, is a promising strengthening alternative 25 for steel structures. The CFRP strands are commercially called as CFRP "FORCA" strands manufactured 26 by the Nippon Steel \& Sumikin Materials Co., LTD, Japan. The CFRP strands are approximately $1.0 \mathrm{~mm}$ 27 (40 mils) in diameter and are stitched together such that small gaps are introduced between the strands.

28 These gaps allow each strand to be completely covered by the epoxy adhesive, thus resulting in a 
superior bonding mechanism. The small-diameter CFRP strands are produced and designated as highmodulus (HM), intermediate-modulus (IM), or low-modulus/high tensile (LM). The CFRP strands are black in color, stitched together using transverse green, blue and yellow woven weft yarn for HM, IM, and LM CFRP strands, respectively.

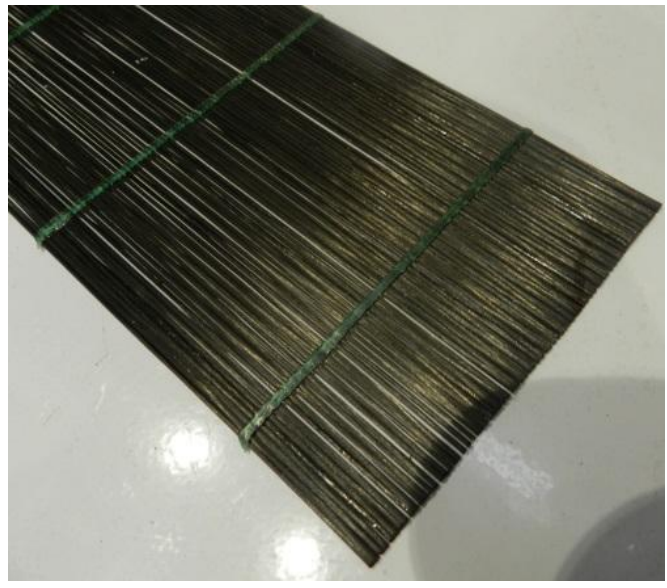

Figure 1: Small-diameter CFRP strand sheet

This paper presents the study recently completed to investigate the effectiveness of these small-diameter CFRP strands to enhance the behavior of steel plates subjected to uniaxial compression. Findings of this study will be expanded to investigate the effectiveness of this system for shear strengthening of steel beams.

\section{Experimental Program}

\subsection{Text Matrix}

The study investigated several parameters believed to influence the effectiveness and behavior of the small-diameter CFRP strengthening system. The study comprises two phases. The first phase investigated the effect of the slenderness ratio (height-to-thickness) of the steel plate, while the second phase investigated the effect of the tensile modulus of the CFRP strands.

In phase I, six different slenderness ratios $(\mathrm{h} / \mathrm{t})$, ranging from 48 to 154 were selected, where $\mathrm{h}$ and $\mathrm{t}$ are the height and thickness of the steel plate, respectively. The small slenderness ratios were selected to represent stocky webs of hot-rolled steel beams, while the large ratios are typically used for built-up 
bridge girders. The width of all tested plates with different slenderness ratios was $500 \mathrm{~mm}(20 \mathrm{in}$.). A total of 14 plates were tested in phase I as given in Table 1. Eight plates were strengthened with high-modulus

$3(\mathrm{HM})$ strands and six plates were un-strengthened and used as control specimens. Due to the large 4 deformations anticipated with buckling of these plates, the effect of using low-modulus polyurea putty on

Table 1: Test matrix of phase I

\begin{tabular}{|c|c|c|c|c|c|}
\hline \multirow{2}{*}{ Plate Designation } & $\mathrm{h}$ & $t$ & \multirow{2}{*}{$h / t$} & \multirow{2}{*}{ Strengthening } & \multirow{2}{*}{ Polyurea Putty } \\
\hline & mm (in.) & $\mathrm{mm}$ (in.) & & & \\
\hline$I-24-1 / 2-U$ & \multirow{7}{*}{$610(24)$} & \multirow{2}{*}{$13(1 / 2)$} & \multirow{2}{*}{48} & NO (CONTROL) & - \\
\hline I-24-1/2-S-P & & & & YES & YES \\
\hline$I-24-3 / 8-U$ & & \multirow{2}{*}{$10(3 / 8)$} & \multirow{2}{*}{64} & NO (CONTROL) & - \\
\hline I-24-3/8-S-P & & & & YES & YES \\
\hline I-24-5/16-U & & \multirow{3}{*}{$8(5 / 16)$} & \multirow{3}{*}{77} & NO (CONTROL) & - \\
\hline I-24-5/16-S-P & & & & YES & YES \\
\hline I-24-5/16-S & & & & YES & NO \\
\hline I-48-1/2-U & \multirow{7}{*}{$1220(48)$} & \multirow{2}{*}{$13(1 / 2)$} & \multirow{2}{*}{96} & $\overline{\mathrm{NO} \text { (CONTROL) }}$ & - \\
\hline I-48-1/2-S-P & & & & YES & YES \\
\hline I-48-3/8-U & & \multirow{2}{*}{$10(3 / 8)$} & \multirow{2}{*}{128} & NO (CONTROL) & - \\
\hline I-48-3/8-S-P & & & & YES & YES \\
\hline $\mid-48-5 / 16-U$ & & \multirow{3}{*}{$8(5 / 16)$} & \multirow{3}{*}{154} & NO (CONTROL) & - \\
\hline I-48-5/16-S-P & & & & YES & YES \\
\hline I-48-5/16-S & & & & YES & NO \\
\hline
\end{tabular}

14 Phase II investigated the effect of the elastic modulus of the small-diameter CFRP strands. Three 15 different elastic moduli were investigated, namely High-Modulus (HM), Intermediate-Modulus (IM) and 16 debonding capacity of the CFRP strands was also investigated. A Layer of the low-modulus polyurea putty was applied between the steel plate and the CFRP strands for selected specimens to avoid galvanization process. It is believed that the galvanization process take place only in the case of direct contact of the cross section of the carbon fibers to the steel plate. For the proposed strengthening system, the fibers are parallel to the surface and totally separated from the steel by using the primer, polyurea putty and epoxy adhesive to bond the strands to the steel surface. This fact is confirmed by the use of CFRP stirrups for steel pre-stressed concrete girder bridges built in 1993 without any sign of galvanic corrosion up to date [18]. 
II as given in Table 2 with a total of 18 specimens. Six plates were strengthened with one layer of either HM, IM, or LM CFRP strands on each face of the plate. In addition, six plates were strengthened with two layers of either HM, IM, or LM small-diameter CFRP strands on each face of the plate. The remaining six plates were not strengthened and used as control specimens. All of the plates tested in Phase II contained a single layer of polyurea putty applied between the steel plate and the first layer of the CFRP strands.

Table 2: Test matrix of phase II

\begin{tabular}{|c|c|c|c|c|c|}
\hline \multirow{2}{*}{ Plate Designation } & $\mathbf{h}$ & $t$ & \multirow[t]{2}{*}{$h / t$} & \multirow[t]{2}{*}{ Fiber Type } & \multirow[t]{2}{*}{ CFRP Layer } \\
\hline & mm (in.) & mm (in.) & & & \\
\hline II-24-5/16-LM-U & \multirow{9}{*}{$610(24)$} & \multirow{9}{*}{$8(5 / 16)$} & \multirow{9}{*}{77} & NO (CONTROL) & NO \\
\hline II-24-5/16-IM-U & & & & NO (CONTROL) & NO \\
\hline II-24-5/16-HM-U & & & & NO (CONTROL) & NO \\
\hline II-24-5/16-1LM & & & & LM & 1 \\
\hline II-24-5/16-1IM & & & & IM & 1 \\
\hline II-24-5/16-1HM & & & & $\mathrm{HM}$ & 1 \\
\hline II-24-5/16-2LM & & & & LM & 2 \\
\hline II-24-5/16-2IM & & & & IM & 2 \\
\hline II-24-5/16-2HM & & & & $\mathrm{HM}$ & 2 \\
\hline II-48-5/16-LM-U & \multirow{9}{*}{$1220(48)$} & \multirow{9}{*}{$8(5 / 16)$} & \multirow{9}{*}{154} & NO (CONTROL) & $\mathrm{NO}$ \\
\hline II-48-5/16-IM-U & & & & NO (CONTROL) & $\mathrm{NO}$ \\
\hline II-48-5/16-HM-U & & & & NO (CONTROL) & NO \\
\hline II-48-5/16-1LM & & & & LM & 1 \\
\hline II-48-5/16-1IM & & & & IM & 1 \\
\hline II-48-5/16-1HM & & & & $\mathrm{HM}$ & 1 \\
\hline II-48-5/16-2LM & & & & LM & 2 \\
\hline II-48-5/16-2IM & & & & IM & 2 \\
\hline II-48-5/16-2HM & & & & $\mathrm{HM}$ & 2 \\
\hline
\end{tabular}

\section{8}

\subsection{Material Properties}

\subsubsection{Steel}

All test plates were high-strength, low-alloy, ASTM A572 Grade 50 steel. Tensile coupons were prepared and tested according to ASTM A370 [19] in order to determine the mechanical properties. Three coupons were tested from each of the three plate thicknesses. The measured tensile properties of the test steel plates with different thicknesses are given in Table 3. 
Table 3: Summary of average measured tensile characteristics of steel

\begin{tabular}{|c|c|c|c|}
\hline Nominal Thickness & Yield Strength & Modulus of Elasticity & Yield Strain \\
\hline $\mathbf{m m}$ (in.) & MPa (ksi) & MPa (ksi) & mm/mm (in./in.) \\
\hline $\mathbf{1 3 ( 1 / 2 )}$ & $441(64)$ & $194,269(28,176)$ & 0.00229 \\
\hline $\mathbf{1 0 ( 3 / 8 )}$ & $455(66)$ & $199,925(28,996)$ & 0.00227 \\
\hline $\mathbf{8 ( 5 / 1 6 )}$ & $393(57)$ & $198,661(28,813)$ & 0.00202 \\
\hline
\end{tabular}

4

5

6

\subsubsection{CFRP}

Tension specimens were prepared using an individual strand in accordance with ASTM D3039 [20] and Test Method L2 of ACl 440.3R-04 [21]. The average cross-sectional areas of the individual CFRP strands, are given in Table 4. The cross-sectional area was determined by water volume displacement of 15 randomly extracted individual strands. Due to the difficulty of attaching the extensometer to an individual strand, the elongations of the strands were measured by using OptotrakCertus $\circledast$ motion capturing system. Each coupon had two InfraRed Emitting Diodes (IREDs) attached to the individual strand to measure the elongation. The average measured tensile stress and strain of the various CFRP strands are summarized in Table 4 and the stress-strain relationship is shown in Figure 2. Three coupons were tested from each of the three types of CFRP strands. It is worth noting that the rupture strain of the $\mathrm{HM}$ strands was larger than the measured yield strain of the steel.

The compressive characteristics of the three types of CFRP strands were also determined. Coupons cut from the CFRP witness panels were tested to define the properties of the composite materials. Witness panels were fabricated under the same environmental conditions used for the strengthening system used for the steel test plates. Compressive specimens were prepared in accordance with ASTM D6641 [22] and tested in compression. Shortening of the witness panels coupons were measured using tee rosette strain gauges. The CFRP strands were positioned in the longitudinal direction parallel to the compressive applied load. Three coupons were tested from each of the three types of CFRP strands. The average measured compressive properties of the various CFRP witness panels are summarized in Table 5 and shown in Figure 3. Material properties of the putty and epoxy adhesive are reported by Okuyama et al. 
(2012) [23]. The chemical properties and mechanical compatibility between putty, epoxy adhesive and

2 CFRP strands are addressed in detail by Komori et al. (2013) [24].

Table 4: Measured tensile properties of small-diameter CFRP strands

\begin{tabular}{|c|c|c|c|c|}
\hline \multirow{2}{*}{ CFRP Strand } & Strand Area & Rupture Strain & Rupture Stress & Elastic Modulus \\
\cline { 2 - 5 } & $\mathbf{m m}^{2}$ (in $\left.^{2}\right)$ & $\mathbf{m m} / \mathbf{m m}$ (in./in.) & $\mathbf{M P a}(\mathbf{k s i})$ & $\mathbf{M P a}(\mathbf{k s i})$ \\
\hline $\begin{array}{c}\text { Low-Modulus } \\
\text { (LM) }\end{array}$ & $\begin{array}{c}1.03226 \\
(0.00156)\end{array}$ & 0.0168 & $2,353(341)$ & $\begin{array}{c}140,253 \\
(20,342)\end{array}$ \\
\hline $\begin{array}{c}\text { Intermediate-Modulus } \\
\text { (IM) }\end{array}$ & $\begin{array}{c}1.23871 \\
(0.00192)\end{array}$ & 0.0104 & $2,220(322)$ & $\begin{array}{c}212,752 \\
(30,857)\end{array}$ \\
\hline $\begin{array}{c}\text { High-Modulus } \\
\text { (HM) }\end{array}$ & $\begin{array}{c}1.14193 \\
(0.00177)\end{array}$ & 0.0032 & $806(117)$ & $\begin{array}{l}255,430 \\
(37,047)\end{array}$ \\
\hline
\end{tabular}

4

Table 5: Measured compressive properties of CFRP witness panels

\begin{tabular}{|c|c|c|c|}
\hline CFRP Witness Panel & Area & Compressive Strength & Elastic Modulus \\
\cline { 2 - 4 } & $\mathbf{m m}^{2}$ (in $\left.^{2}\right)$ & $\mathbf{M P a}$ (ksi) & $\mathbf{M P a}(\mathbf{k s i})$ \\
\hline $\begin{array}{c}\text { Low-Modulus } \\
\text { (LM) }\end{array}$ & $\begin{array}{c}56.765 \\
(0.0880)\end{array}$ & $95.29(13.82)$ & $24,766(3,592)$ \\
\hline $\begin{array}{c}\text { Intermediate-Modulus } \\
\text { (IM) }\end{array}$ & $\begin{array}{c}60.855 \\
(0.0943)\end{array}$ & $121.44(17.61)$ & $40,987(5,945)$ \\
\hline $\begin{array}{c}\text { High-Modulus } \\
\text { (HM) }\end{array}$ & $\begin{array}{c}70.518 \\
(0.1093)\end{array}$ & $69.89(10.14)$ & $47,358(6,869)$ \\
\hline
\end{tabular}

6

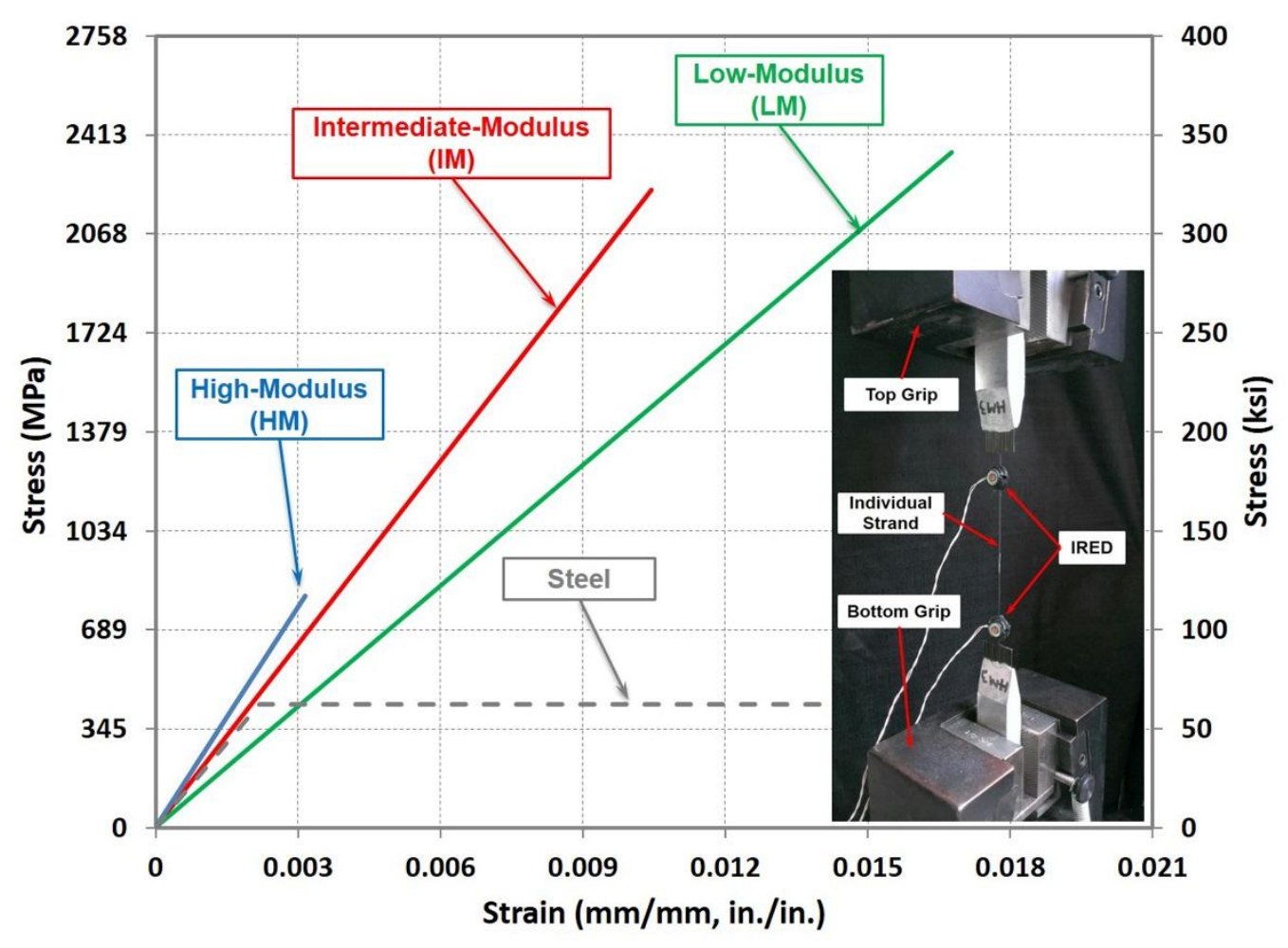


Figure 2: Typical tensile stress-strain behavior of the three types of CFRP strands

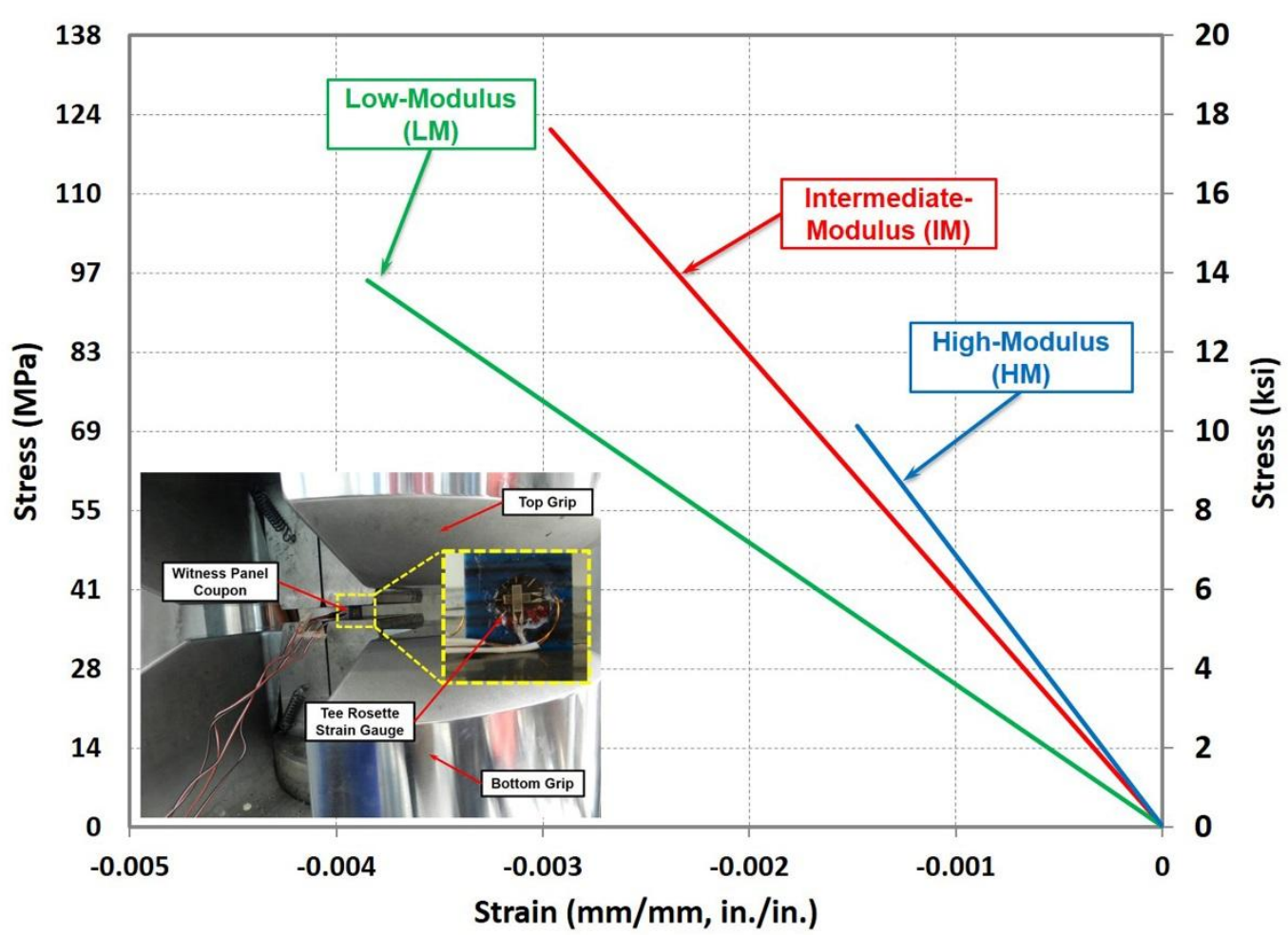

Figure 3: Typical compressive stress-strain behavior of the three types of CFRP witness panels

\subsection{Test Setup}

A special, self-reacting A-frame was designed and fabricated to subject the test plates to uniaxial compression and to provide a well-defined end conditions for the test plates. The test specimens consisted of a steel plate welded at both ends to $13 \mathrm{~mm}(1 / 2 \mathrm{in}$.$) thick high-strength steel tubes$ (hereinafter referred to as sleeves) with an inner diameters of $152 \mathrm{~mm}$ (6 in.). The sleeves were free to rotate around high-strength solid steel pins to simulate hinge-hinge boundary condition for the test steel plate. The friction between the pins and the sleeves was virtually eliminate using chrome-painted surfaces for the pins as well as greasing the surfaces of the pins and cylinders before each test. The same boundary conditions were maintained for all tested specimens in this study. The hinge-hinge boundary condition was selected to reduce the magnitude of the buckling load and to provide reliable and well-

14 defined system to calibrate the analytical model which was used to study other parameters not 15 considered in the experimental program. 
The Load was applied to the pins using two high-strength steel pre-stressing bars (hereinafter referred to as HS bars), connected to two hydraulic jacks. The load was transferred from the pins to the sleeves by bearing and then from the sleeves to the test plate through the weld. The hydraulic jacks were simultaneously connected to the same hydraulic pump to ensure equal loads on both HS bars, hence subjecting the test plate to uniform compressive stresses. The applied load was in controlled mode using displacement rate of $0.125 \mathrm{~mm} / \mathrm{min}(0.005 \mathrm{in} . / \mathrm{min})$. The entire test fixture was maintained in vertical position by guiding the pins to move between the two vertical legs of the supporting A-frame as shown in Figure 4. The supporting A-frame was tied down to the laboratory strong floor at four locations to ensure the stability during testing. Figure 4 shows an elevation and side views of the test setup as well as the different parts of the test setup.

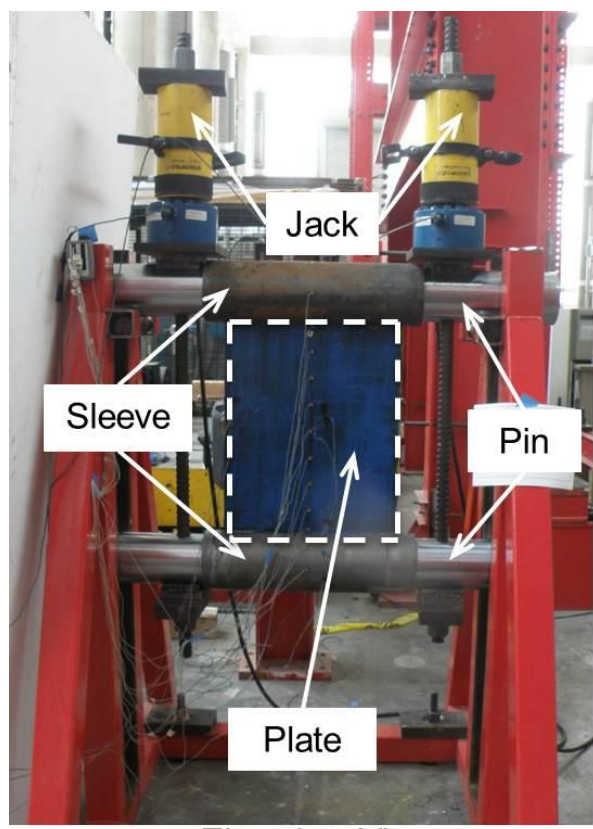

Elevation View

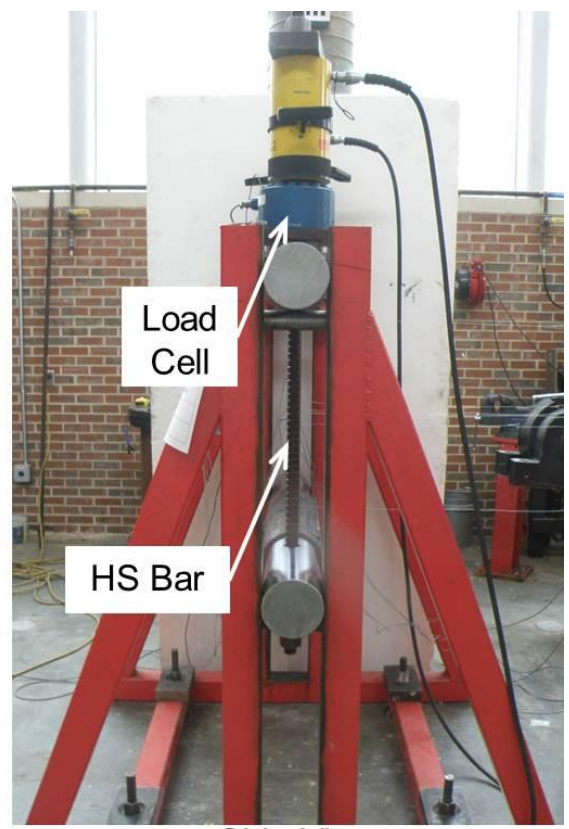

Side View

Figure 4: Test setup for uniaxial compression testing of plates

The applied load was measured using load cells mounted on each HS bar. Strains of the steel plate specimens were measured using electrical resistance strain gauges with a gauge length of $5 \mathrm{~mm}(3 / 16$ in.) and gauge resistance of $120 \pm 0.5$ ohms. Four strain gauges were attached to un-strengthened specimens at mid-height, with two strain gauges on each face. One strain gauge was attached at the edge of the plate and the second strain gauge was located at the centerline of the plate. A total of eight 
strain gauges were attached to each strengthened specimen at mid-height. Four strain gauges were attached to the base steel before application of the strengthening system. The remaining four strain gauges were attached to the outer surface of the CFRP strand sheets after curing of the epoxy resin. For specimens with two layers of CFRP strands, strain gauges were applied to the outer-most layer of CFRP strands only. Figure 5 shows the cross-section of the strengthened test plate displaying the location of the strain gauges applied at mid-height.

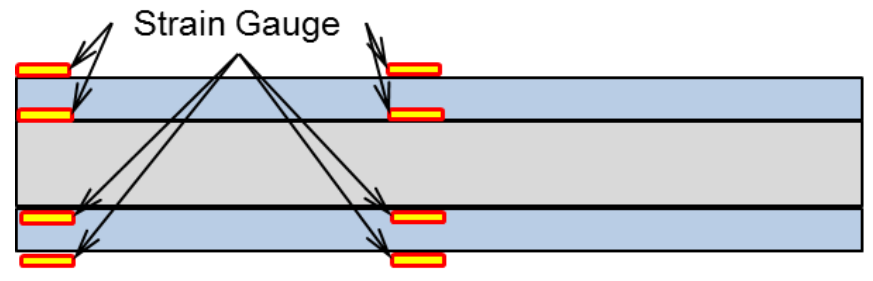

CFRP Strands Layer Steel Plate CFRP Strands Layer

Figure 5: Cross-section of test plates at mid-height showing location of strain gauges

Lateral deflections along the vertical centerline of the specimens were measured using linear string potentiometers with a stroke range of $317 \mathrm{~mm}(12.5 \mathrm{in}.) \pm 0.25 \%$. Four string potentiometers were used, one attached to the top of the plate, one to the bottom, and two at mid-height. The spatial deformation of the test plate during loading was monitored and measured using a three-dimensional (3-D) OptotrakCertus ${ }^{\circledR}$ motion capturing system. The motion capturing system creates a 3-D coordinate system by the use of Infrared Emitting Diodes (IRED) attached to the specimen at points of interest. Any subsequent movement of the IREDs is captured by the camera system in reference to the established coordinate. The Optotrak system has an accuracy of $0.1 \mathrm{~mm}(0.004 \mathrm{in}$.) and resolution of $0.01 \mathrm{~mm}$ (0.0004 in.). The IREDs were attached to the front face of the test plates along the vertical centerline and were spaced vertically at $75 \mathrm{~mm}$ (3 in.). One IRED was also attached to each sleeve to monitor their movement, and hence determine their rotation. Figure 6 shows the different instrumentation used for all plates included in this study. All instrumentations were connected to an electronic data acquisition system. 


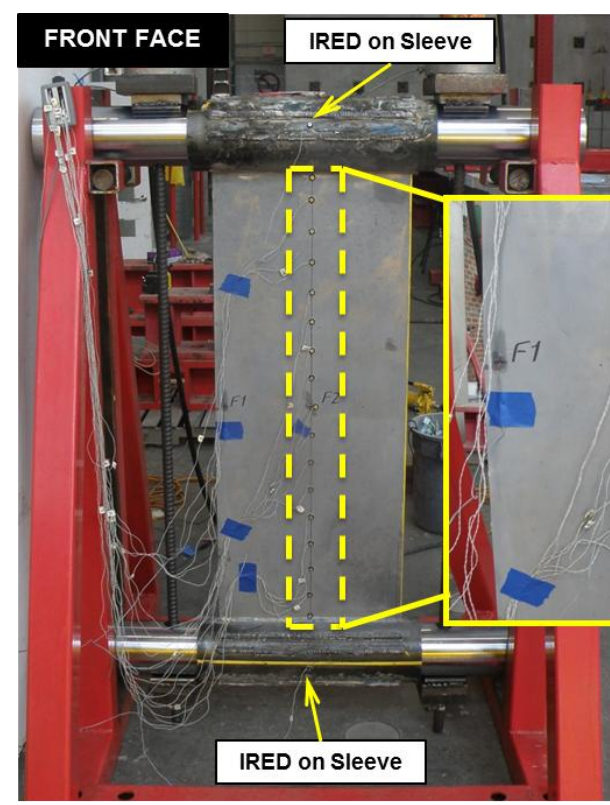

(a)
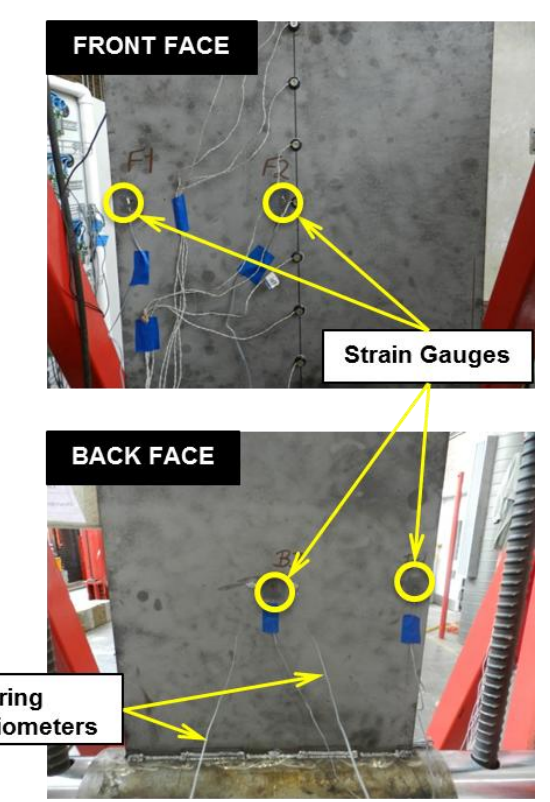

(b)

Figure 6: Specimen instrumentation, a) IREDs attached on the front face of test plate, b) string potentiometers attached to the back face, strain gauges on both faces of test plate

\section{Application of the Strengthening System}

Application of the CFRP strands followed a procedure recommended by the manufacturer as illustrated in Figure 7. Initially, the steel plates were sandblasted prior to the commencement of the application process. The strain gages were attached to the steel plate after the plates were cleaned using pressurized air. The primer resin was applied to the steel plates after sandblasting and cleaning. The polyurea putty layer was applied after at least two hours from the application of the primer resin. The epoxy was applied after at least six hours from the application of the polyurea putty layer. Application of epoxy was performed while the steel plate was in horizontal position. After applying the epoxy layer, the CFRP sheets cut to predetermined length were bonded to the steel plate. The strain gauge leading wires were passed through the gap between the strands. The applied CFRP sheet was firmly pressed using hand rollers until the excessive epoxy was squeezed out to ensure the elimination of any air pocket. A second layer of epoxy was applied on the top of the CFRP sheets. Finally, the strengthened plate remained in control environment for at least seven days to cure before it was tested. 


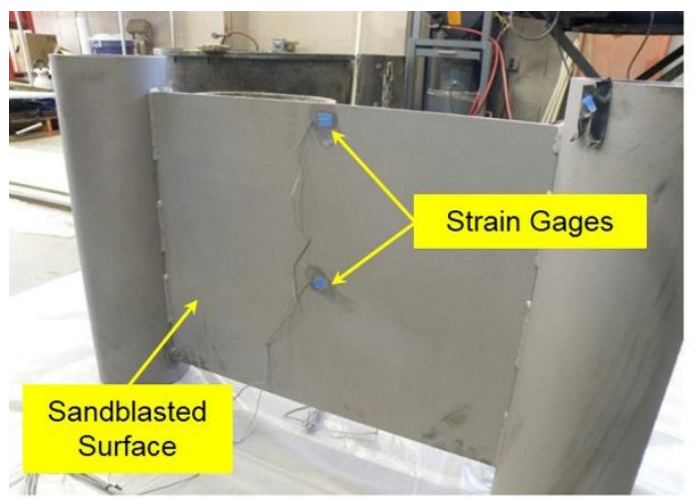

(a)

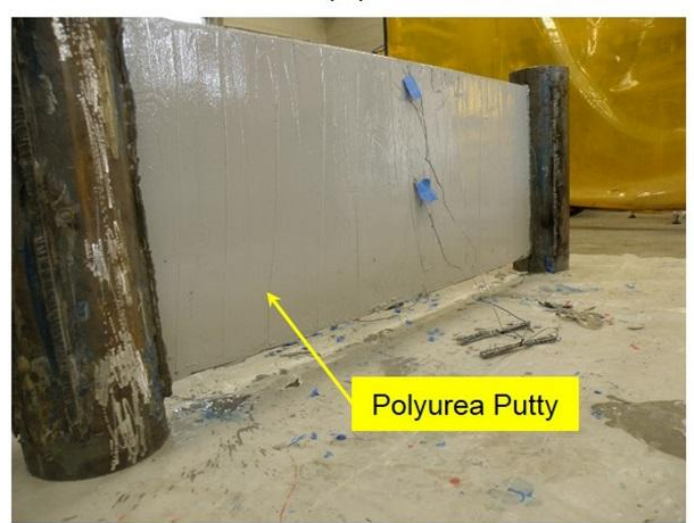

(c)

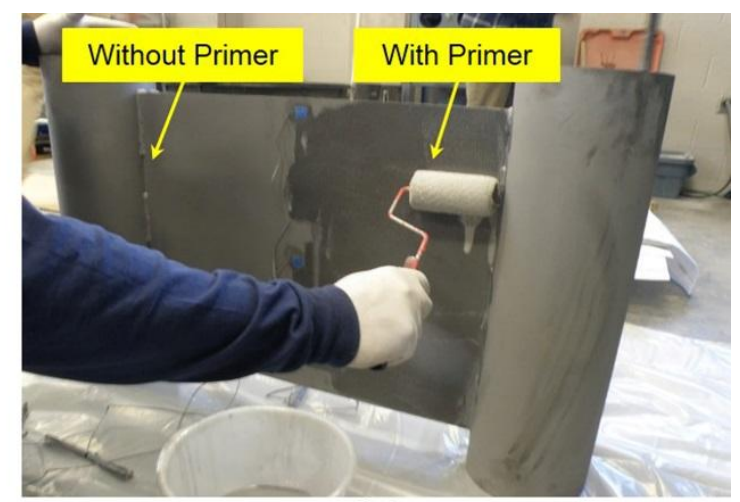

(b)

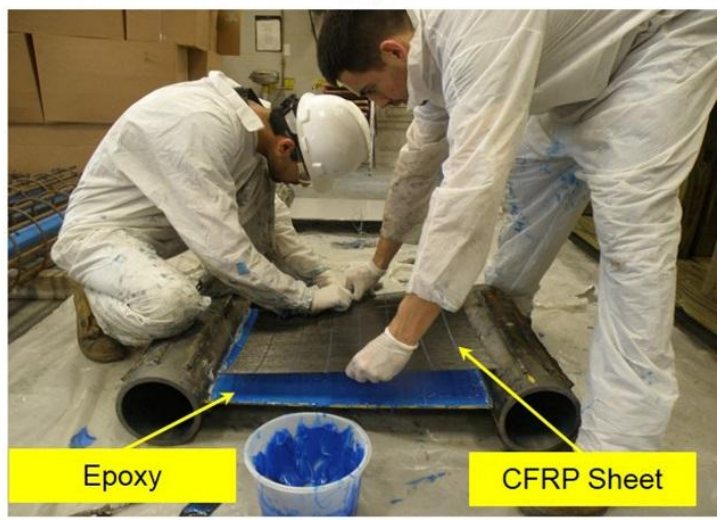

(d)

Figure 7: Application of strengthening system, a) Sandblasted steel plate, b) Application of primer resin, c) Application of polyurea putty, d) Application of epoxy and attaching the CFRP sheet

\section{Test Results and discussion of Phase I}

Since the free edges along the direction of the applied compressive load, the behavior of the plate is expected to be similar to columns and the column buckling equations can be implemented [25, 26]. Due to imperfection of the plate, it deforms before reaching the buckling load $\left(\mathrm{P}_{\mathrm{b}}\right)$ of a perfect plate with the same boundary condition. Therefore, buckling will not be instantaneous occurrence; rather it is a gradual process until an ultimate load is reached. In this case, $\mathrm{P}_{\mathrm{b}}$ of the perfect structure is replaced by an ultimate load which is very close to $\mathrm{P}_{\mathrm{b}}$. Despite not being equal in value, the ultimate load is defined as the buckling load [25]. Figure 8 shows the behavior of a perfect and imperfect plate under the effect of the axial compressive loading conditions used in the test setup. 


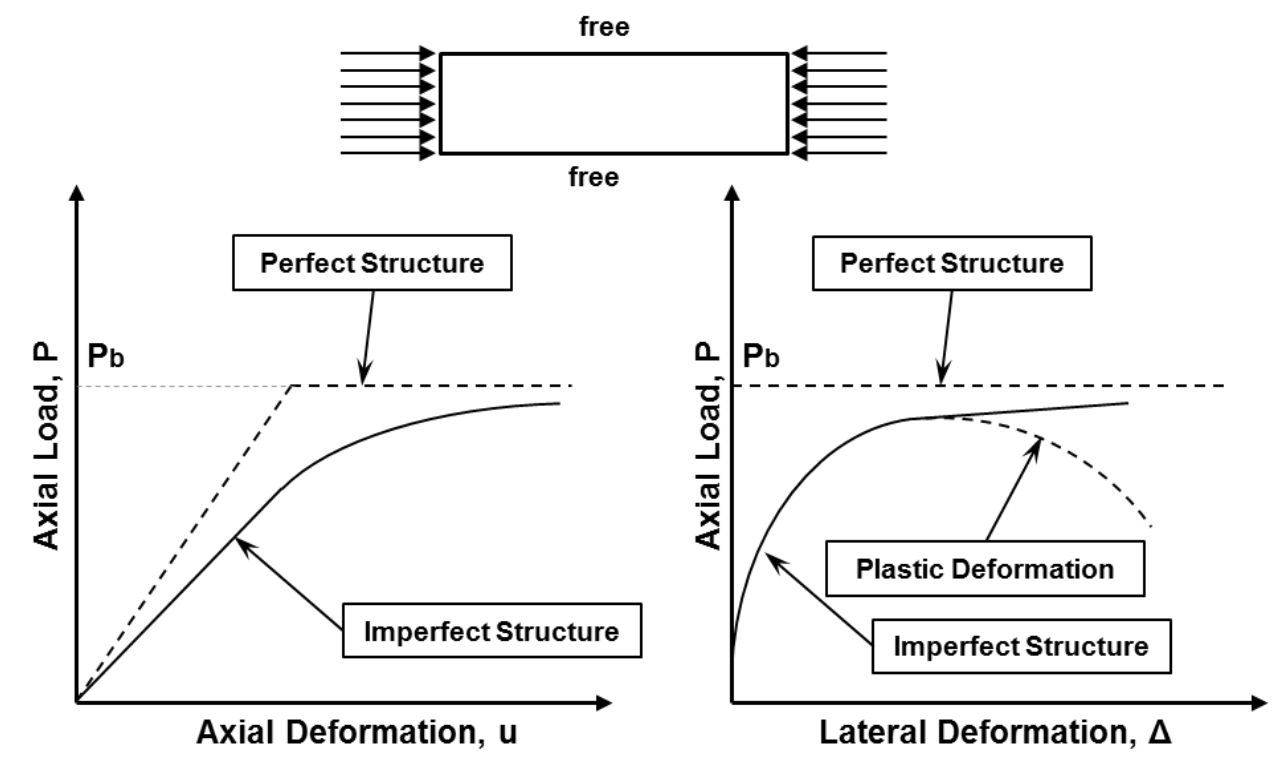

1

Figure 8: Typcial Behavior of steel column with and without imperfection [26]

The initial imperfections, which affected test results, could be the results of rapid and uneven cooling of steel after rolling [27], welding the plate to the sleeves at both ends, imposed eccentricities due to errors conducted by keeping the plate at the centerline of the both sleeves, and application of the CFRP strengthening system since it is not a machined process. Using recorded data from the Optotrak system, out-of-straightness imperfections were captured. Measured initial imperfections with respect to its ends are shown in Figure 9. The measured values clearly indicate that imperfections are not identical for the tested specimens.

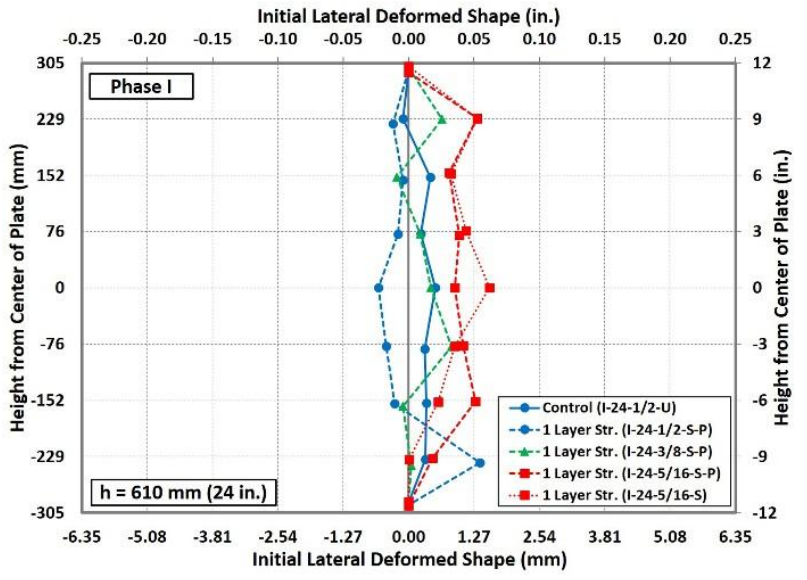

(a)

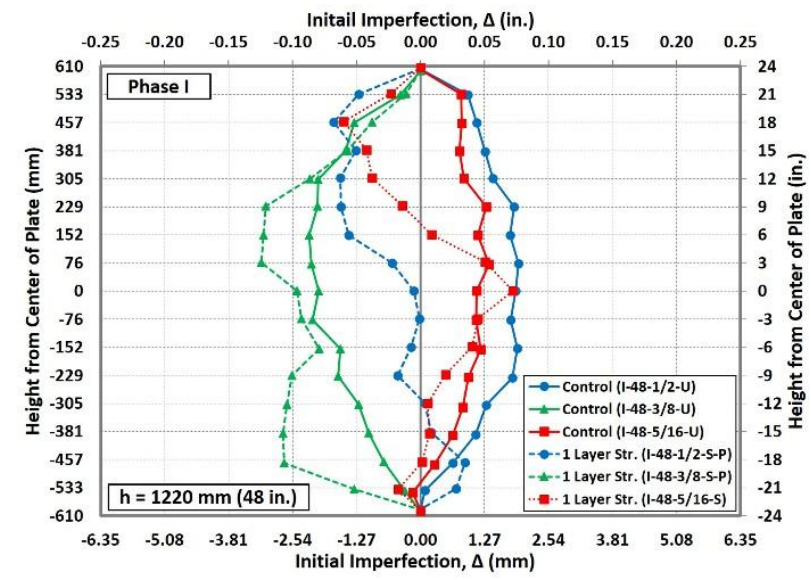

(b)

Figure 9: Measured initial imperfection of the specimens at Phase I having heights of, a) $h=610 \mathrm{~mm}$ (24in.), b) $h=1220 \mathrm{~mm}$ (48in.) 


\subsection{Buckling Load}

2 The Buckling load of strengthened plates was compared to the buckling load of un-strengthened control

3 plates. The measured buckling load of Phase I are given in Table 6. In addition, the percentage increase

4 of the buckling loads for different slenderness ratios are given in the same table and shown in Figure 10.

5 Test results indicate that using one layer of HM CFRP strands could increase the buckling capacity up to

661 percent. It is observed that the effectiveness of the CFRP strands to increase the buckling load of steel

7 plates is dependent on the slenderness ratio of the steel plate. Discrepancy of the percentage increase is

8 due to the different imperfection of the tested plates.

Table 6: Test results summary of Phase I

\begin{tabular}{|c|c|c|c|}
\hline \multirow{2}{*}{ Plate Designation } & \multirow{2}{*}{$h / t$} & \multicolumn{2}{|c|}{ Buckling Load } \\
\hline & & kN (kip) & Increase (\%) \\
\hline I-24-1/2-U & \multirow{2}{*}{48} & $645(145)$ & - \\
\hline I-24-1/2-S-P & & $787(177)$ & 22 \\
\hline I-24-3/8-U & \multirow{2}{*}{64} & $374(84)$ & - \\
\hline I-24-3/8-S-P & & $430(97)$ & 15 \\
\hline I-24-5/16-U & \multirow{3}{*}{77} & $210(47)$ & - \\
\hline I-24-5/16-S-P & & $295(66)$ & 40 \\
\hline I-24-5/16-S & & $325(73)$ & 55 \\
\hline I-48-1/2-U & \multirow{2}{*}{96} & $112(25)$ & - \\
\hline I-48-1/2-S-P & & $176(39)$ & 56 \\
\hline I-48-3/8-U & \multirow{2}{*}{128} & $62(14)$ & - \\
\hline I-48-3/8-S-P & & $89(20)$ & 43 \\
\hline $\mathrm{I}-48-5 / 16-\mathrm{U}$ & \multirow{3}{*}{154} & $58(13)$ & - \\
\hline I-48-5/16-S-P & & $76(17)$ & 31 \\
\hline $\mid-48-5 / 16-S$ & & $93(21)$ & 61 \\
\hline
\end{tabular}




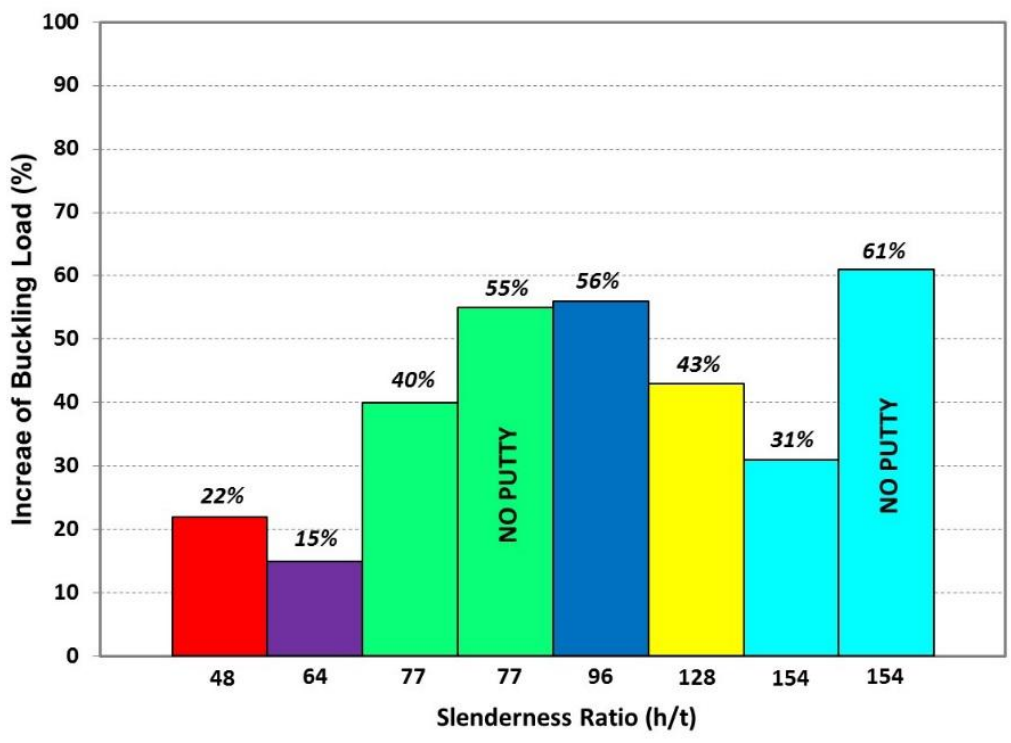

Figure 10: Buckling load increase of strengthened plates of phase I

\subsection{Measured Strain}

4 The average measured longitudinal strains of the steel substrate and the CFRP strengthening material at

5 mid-height of the plates versus the applied axial load are shown in Figure 11 for all test plates with

6 slenderness ratios of 48 through 154. For each specimen, the steel strain of the strengthened plate is

7 compared to the steel strain of the un-strengthened control plate. The CFRP strain of the strengthened

8 specimen is also shown for each specimen. The measured strain shows that the use of externally bonded

9 CFRP strands reduces the strain in the steel plate at the same load level, thus enhancing the buckling

10 load of the plate. Test results indicate also that increasing the applied load induces lateral deflection

11 which is due to initial imperfections of the steel plate.

12 The measured strains reflect the contribution of CFRP strands in the load-carrying mechanism. Figure 11

13 clearly indicates that the measured steel strain of the strengthened plates is generally less than that of the

14 control plate at any given load prior to buckling. None of the tested specimens in Phase I failed due to

15 rupture or debonding of the CFRP strands. This behavior confirms the superior bond characteristics of the 16 small-diameter CFRP strands. 


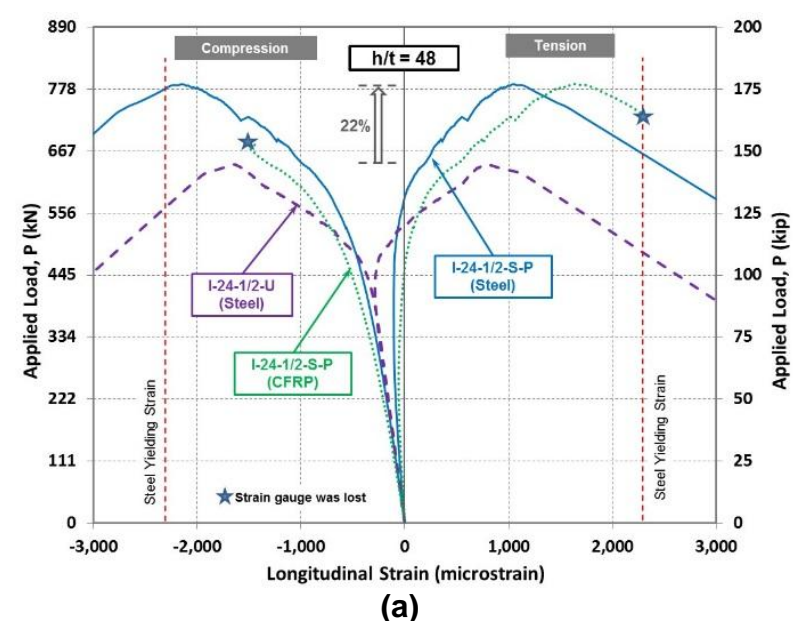

(a)

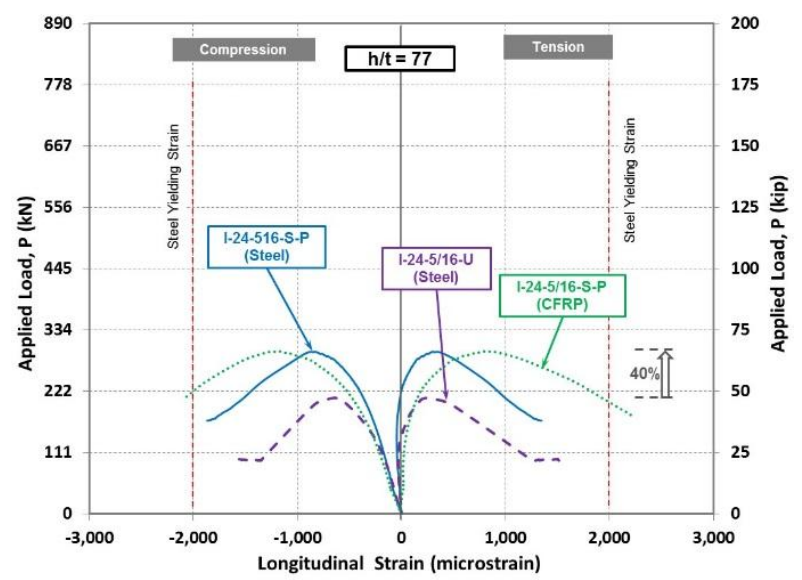

(c)

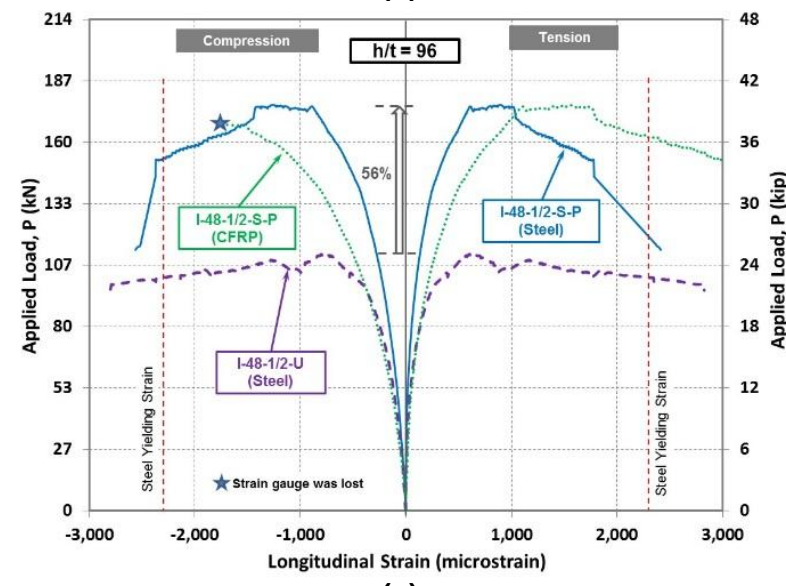

(e)

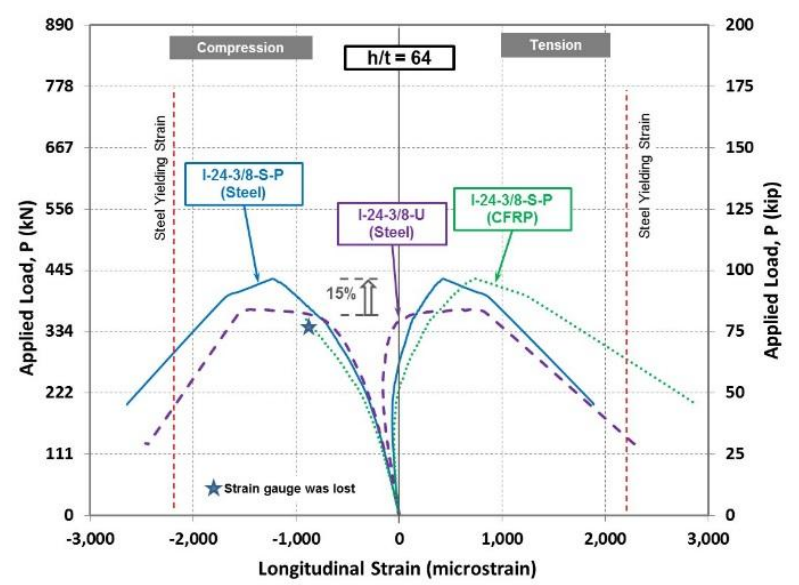

(b)

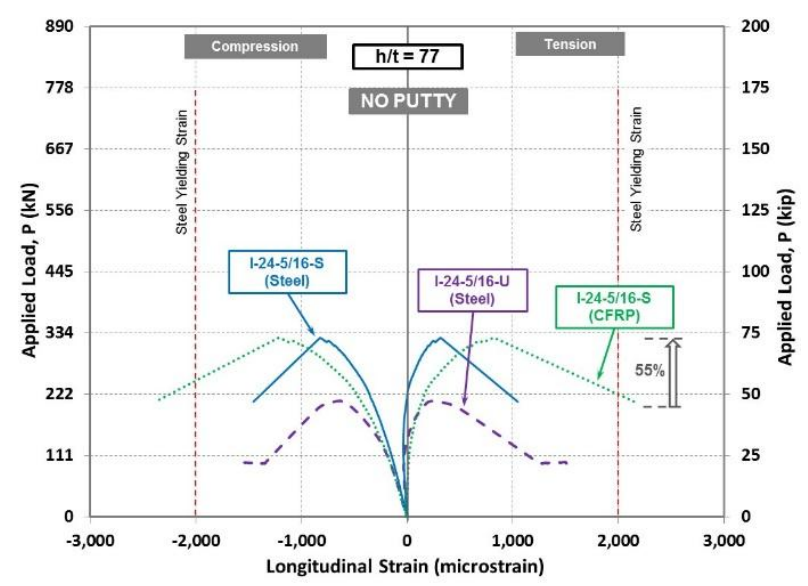

(d)

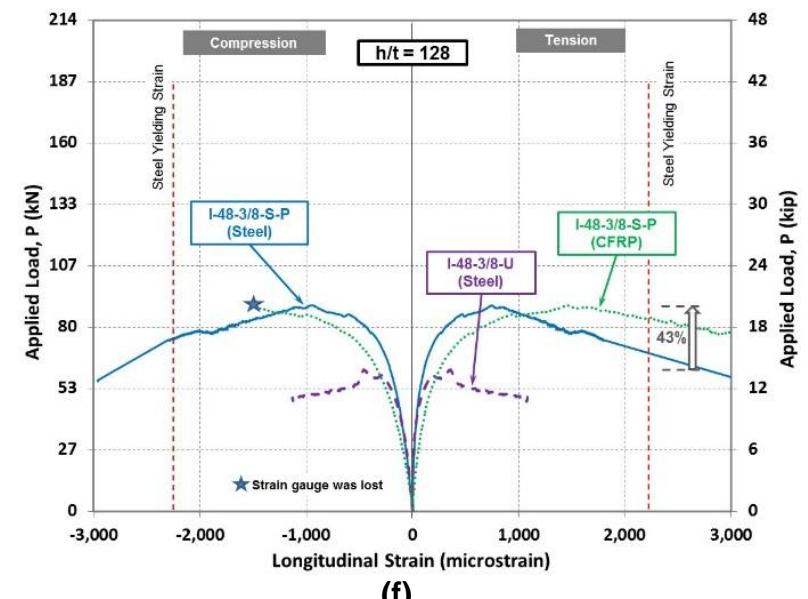

(f) 


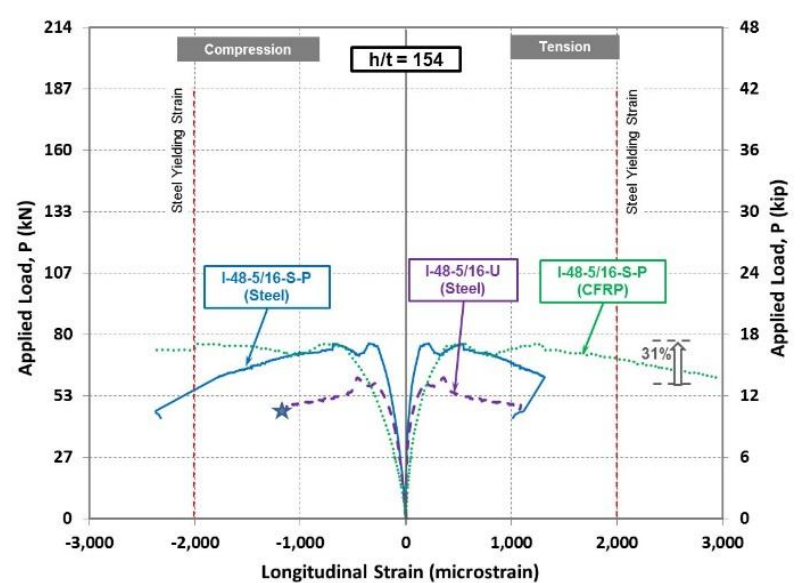

(g)

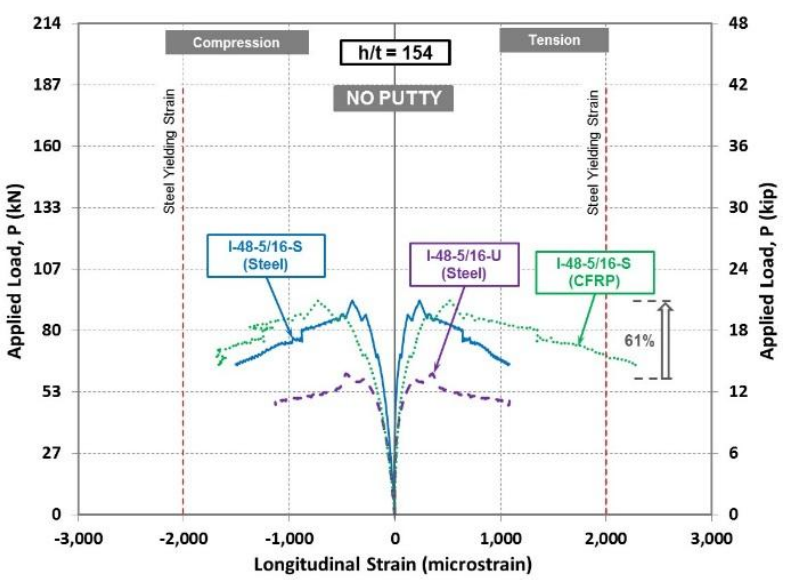

(h)

Figure 11: Applied load vs. Iongitudinal strain at mid-height of plates, a) $h / t=48, b) h / t=64, c) h / t=77, d$ ) $h / t=77$ (no putty), e) h/t=96, f) h/t=128, g) h/t=154, h) h/t=154 (no putty)

\subsection{Load-Deformation Behavior}

6 The net lateral deformation $(\Delta)$ versus the applied axial load is shown in Figure 12 for all test plates. The

7 net lateral deformation was determined using the measured deformation at mid-height, and at the ends of

8 the plate. Captured behavior indicates that increasing the mid-height lateral deformation gradually

9 increased with the increase of the applied load until the onset of buckling occurred. Failure of all test

10 plates was as a result of loss of lateral stability due to large lateral deformation and reduction of load

11 carrying capacity due to buckling. Test results reveal that use of polyurea putty has no significant effect

12 on the efficiency of the CFRP strands strengthening system. This conclusion was drawn based on

13 comparison of the buckling capacity of the plates strengthened with putty compared to those without

14 putty. This behavior can be the result of various imperfections of the test plates. Elimination of polyurea

15 putty layer may minimize the imperfection of the plate and may slightly increase the plate buckling

16 capacity. 


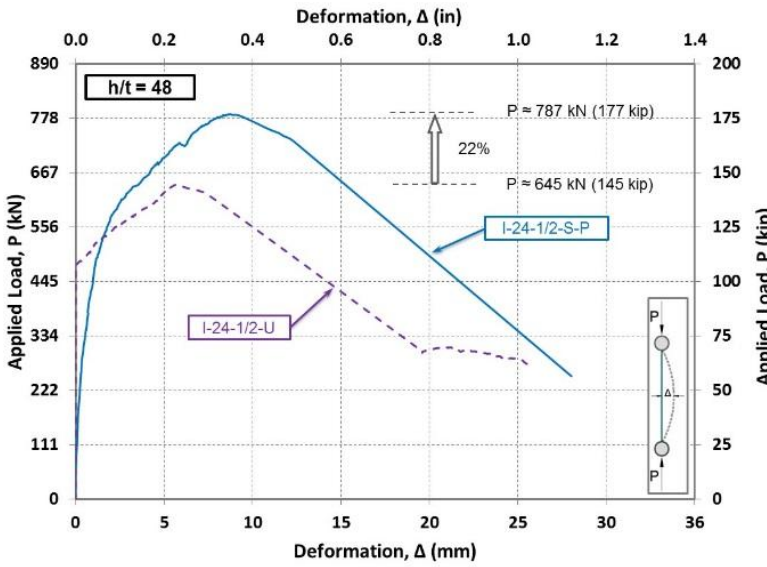

(a)

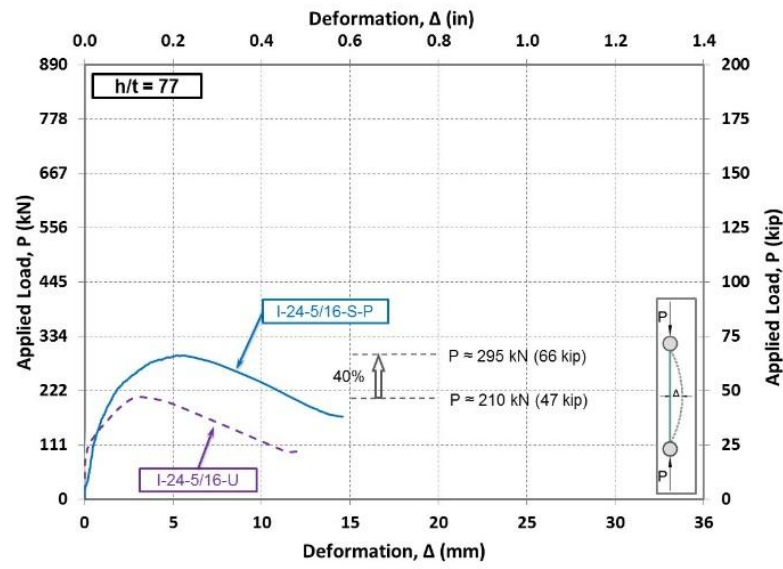

(c)

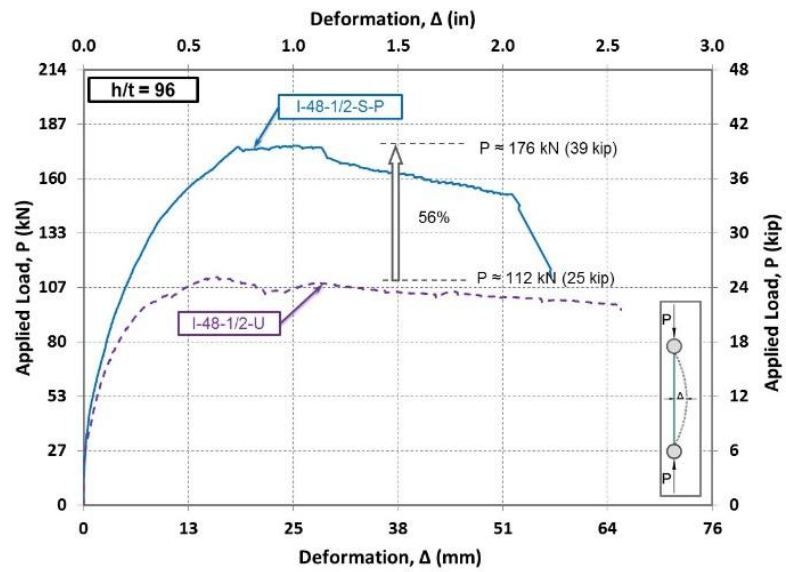

(e)

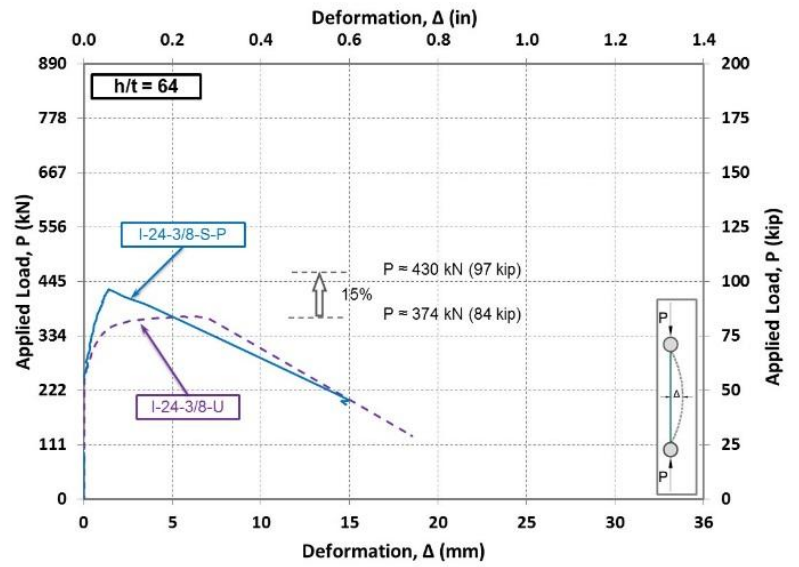

(b)

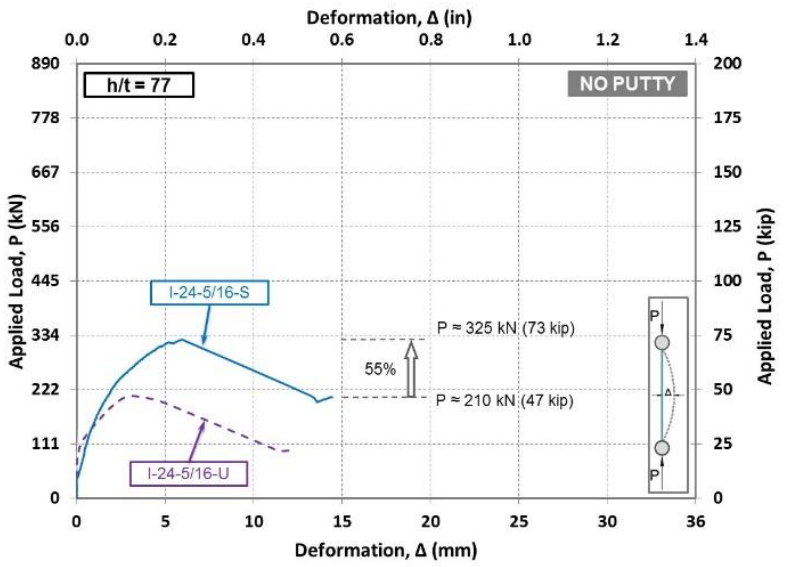

(d)

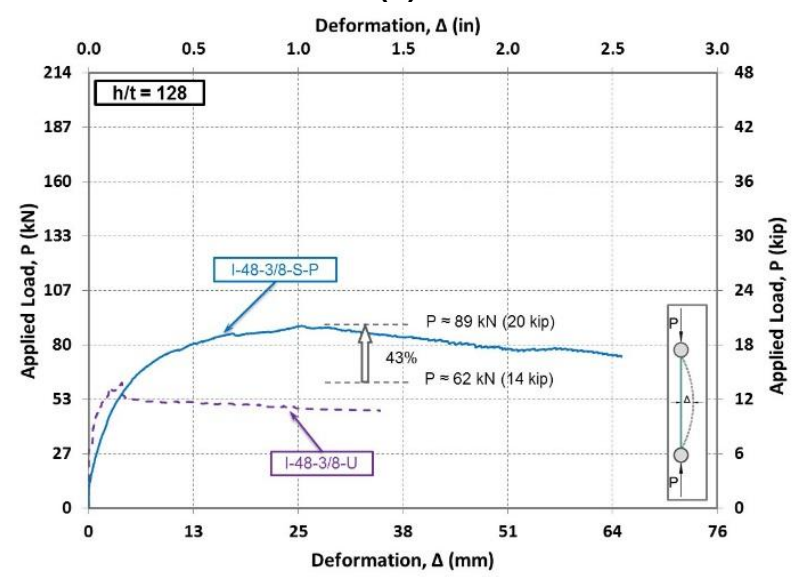

(f) 


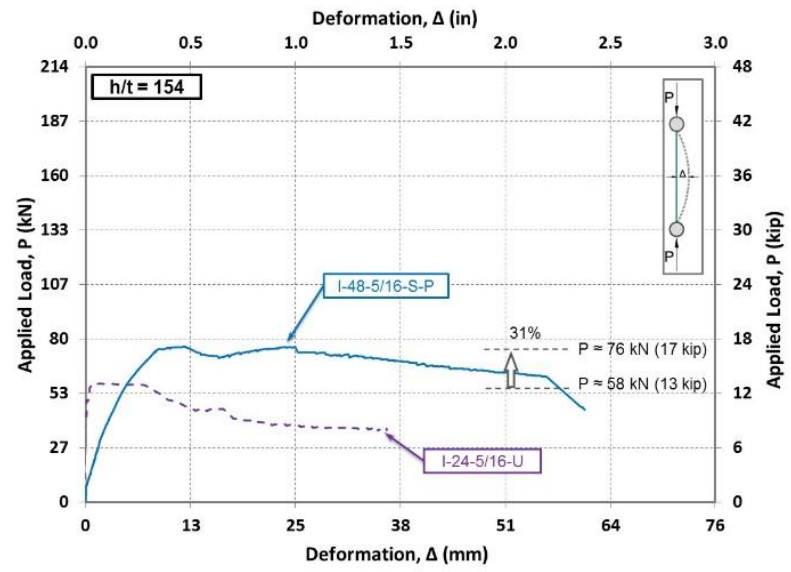

(g)

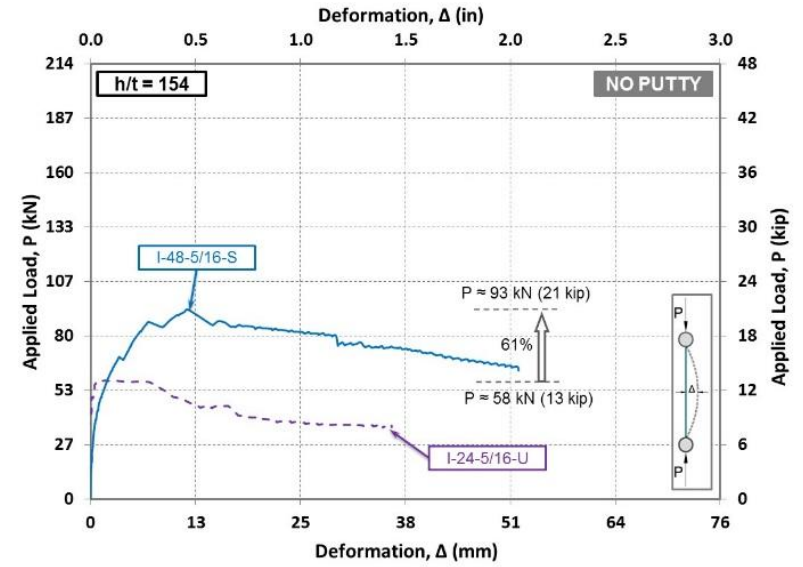

(h)

Figure 12: Applied load vs. mid-height net lateral deformation of plates a) $h / t=48, b) h / t=64, c) h / t=77, d) h / t=77$ (no putty), e) h/t=96, f) h/t=128, g) h/t=154, h) h/t=154 (no putty)

The deflected shapes of the plates with slenderness ratios of 48 and 154 at three load increments measured by the motion capturing system are shown in Figure 13. The behavior was selected at the load levels corresponding to apparent change in lateral stiffness of load-deflection relationships including the load prior to the buckling, at the onset of buckling, and after the buckling. Different curvature observed in the second and third loading level is due to rotation of the sleeves. The loss of load-carrying capacity occurred when the lateral deformation was significantly large in comparison to the deflection at the buckling load stage. In spite of the fact that the deflection at the bottom was not recorded after the buckling, shown in Figure 13 (a) for the third load level, the behavior suggests that the plate was acting as hinge-hinge connection.

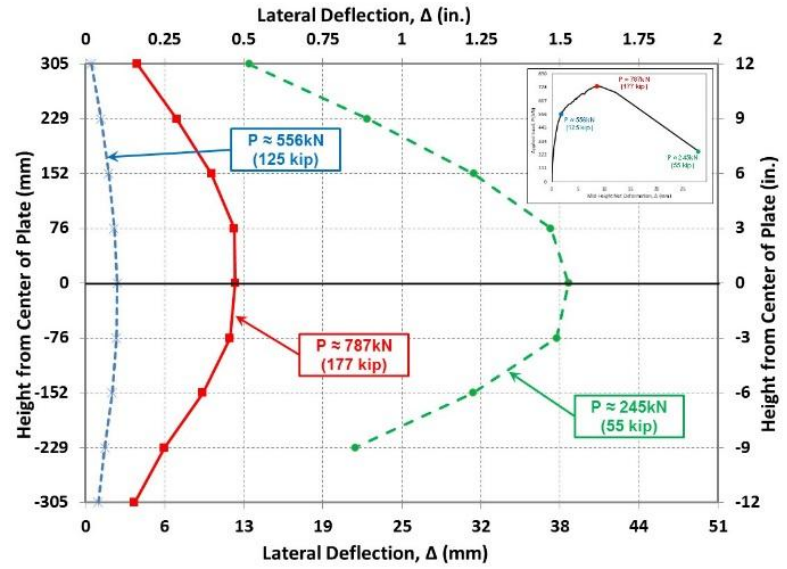

(a)

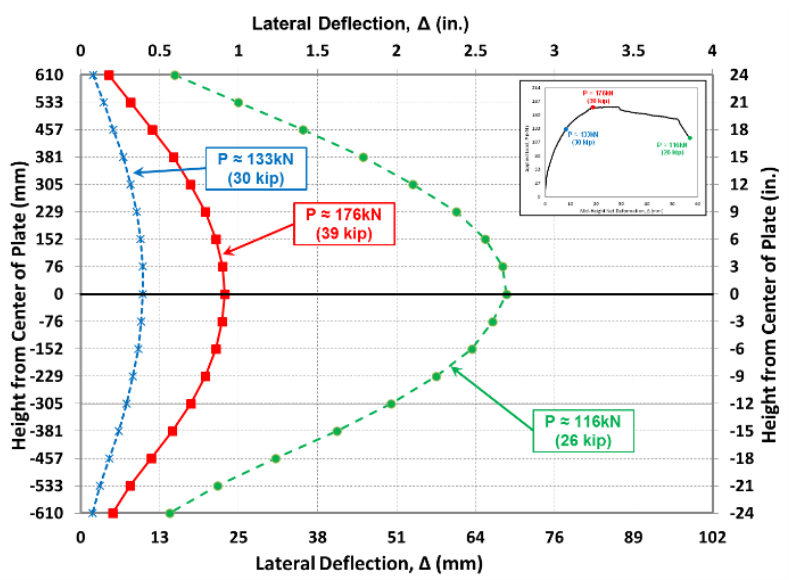

(b)

Figure 13: Height from center of plate vs. lateral deflection of plate, a) IA-24-1/2-S-P (h/t=48), b) IA-48-1/2-S-P $(h / t=96)$ 
No debonding was experienced for all strengthened specimens. Four of the strengthened specimens failed by rupture of the CFRP strands due to the large deformation after buckling. Figure 14 (a) and (b) represent sample of plates with and without rupture of HM CFRP strands due to large deformation after buckling, respectively.

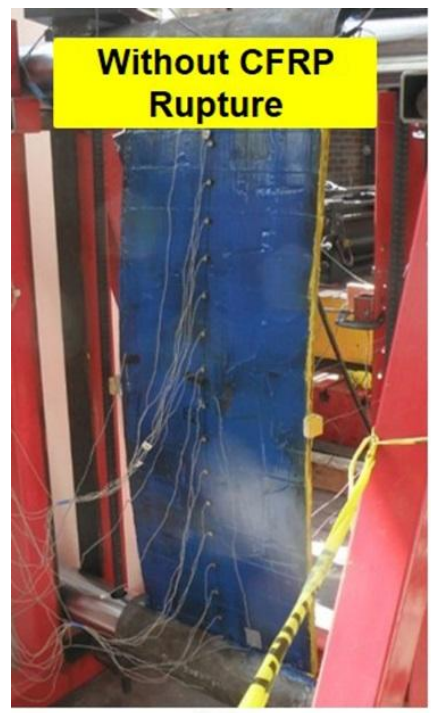

(a)

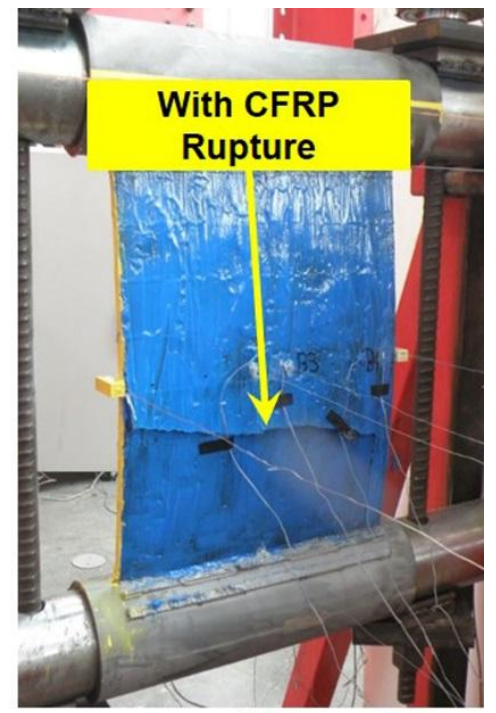

(b)
5 Figure 14: Failure of the strengthening system after large deformation due to buckling, a) Undamaged CFRP
composite of specimen IA-48-5/16-S, b) Rupture of CFRP composite of specimen IA-24-1/2-S-P

The behavior in general indicates that the initial lateral stiffness increases by bonding the CFRP strands to the surface of the steel plates. It was also observed that the behavior is very sensitive to the initial imperfection of the steel plate and could also be effected by thickness variation of the adhesive used on both faces of the plate. This was confirmed by the measurements of the thickness of the witness panels.

\section{Test Results and discussion of Phase II}

Based on the experience gained from the first phase and the fact that the initial imperfections inevitably vary among the steel plates, the same control plates in each category were strengthened and tested to minimize the effect of the initial imperfection of the steel plates on the behavior. Test results of the phase II for the three types of CFRP materials, LM, IM, and HM are given in Table 7. The results are also given for the use of one layer and two layers for each CFRP material type. 
Table 7: Test results summary of Phase II

\begin{tabular}{|c|c|c|c|}
\hline \multirow{2}{*}{ Plate Designation } & \multirow{2}{*}{$h / t$} & \multicolumn{2}{|c|}{ Buckling Load } \\
\hline & & kN (kip) & Increase (\%) \\
\hline II-24-5/16-LM-U & \multirow{9}{*}{77} & $228(51)$ & - \\
\hline II-24-5/16-1LM & & $282(63)$ & 24 \\
\hline II-24-5/16-2LM & & $362(81)$ & 59 \\
\hline II-24-5/16-IM-U & & $233(52)$ & - \\
\hline II-24-5/16-1IM & & $314(71)$ & 35 \\
\hline II-24-5/16-2IM & & $392(88)$ & 68 \\
\hline II-24-5/16-HM-U & & $240(54)$ & - \\
\hline II-24-5/16-1HM & & $343(77)$ & 43 \\
\hline II-24-5/16-2HM & & 458 (103) & 90 \\
\hline II-48-5/16-LM-U & \multirow{9}{*}{154} & $44(10)$ & - \\
\hline II-48-5/16-1LM & & $75(17)$ & 71 \\
\hline II-48-5/16-2LM & & $94(21)$ & 115 \\
\hline II-48-5/16-IM-U & & $52(12)$ & - \\
\hline II-48-5/16-1IM & & $89(20)$ & 71 \\
\hline II-48-5/16-2IM & & $144(32)$ & 178 \\
\hline II-48-5/16-HM-U & & $36(8)$ & - \\
\hline II-48-5/16-1HM & & $78(18)$ & 117 \\
\hline II-48-5/16-2HM & & $165(37)$ & 358 \\
\hline
\end{tabular}

2 Test results of phase II confirms that the bonding of the small-diameter CFRP strands to steel plates

3 increases the buckling capacity of the steel plates. The increase in the buckling load ranged from 24 to

4117 percent for plates strengthened with one layer of CFRP strands and 59 to 358 percent for specimens

5 strengthened with two layers of CFRP strands. Among the three types of CFRP strands, HM CFRP

6 strands were the most effective in increasing the buckling capacity of the steel plates.

7 The applied axial load versus average longitudinal steel strain and net lateral deformation at mid-height

8 for the plates with slenderness ratio of 77 and 154 are shown in Figure 15 and Figure 16, respectively.

9 Behavior of the plates strengthened with LM, IM, and HM CFRP materials is shown in (a), (b), and (c) of

10 each figure, respectively. In each figure, behavior of one layer of CFRP and two layers of CFRP is

11 compared to the control un-strengthened specimen. Due to loss of strain gauges attached to the plates

12 with slenderness ratio of 154 and strengthened with two layers of CFRP strands, the measured strain of

13 the CFRP is used. Results show consistency of the behavior of the three specimens for each type of

14 CFRP. The results indicate also that adding the CFRP layers increases the initial lateral stiffness of the 
1 system. Furthermore, the state of stress in the steel is reduced at any given load prior to the buckling by 2 adding the second layer of CFRP strengthening system.
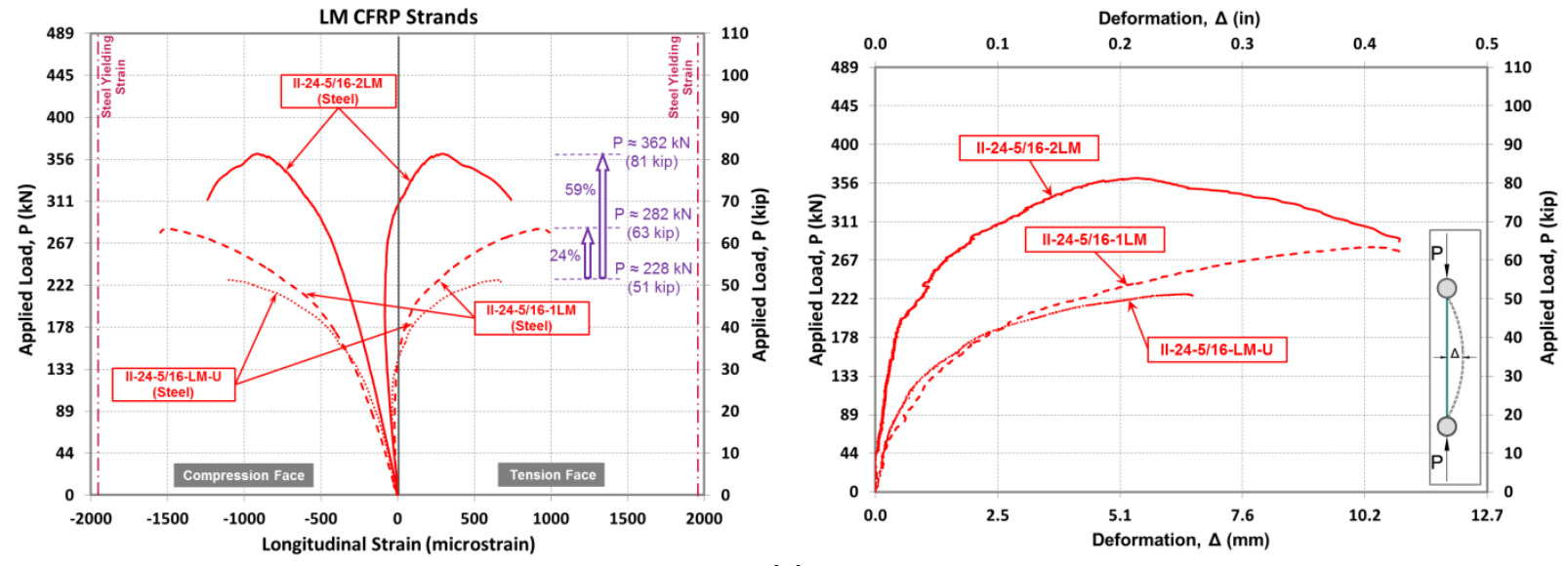

(a)
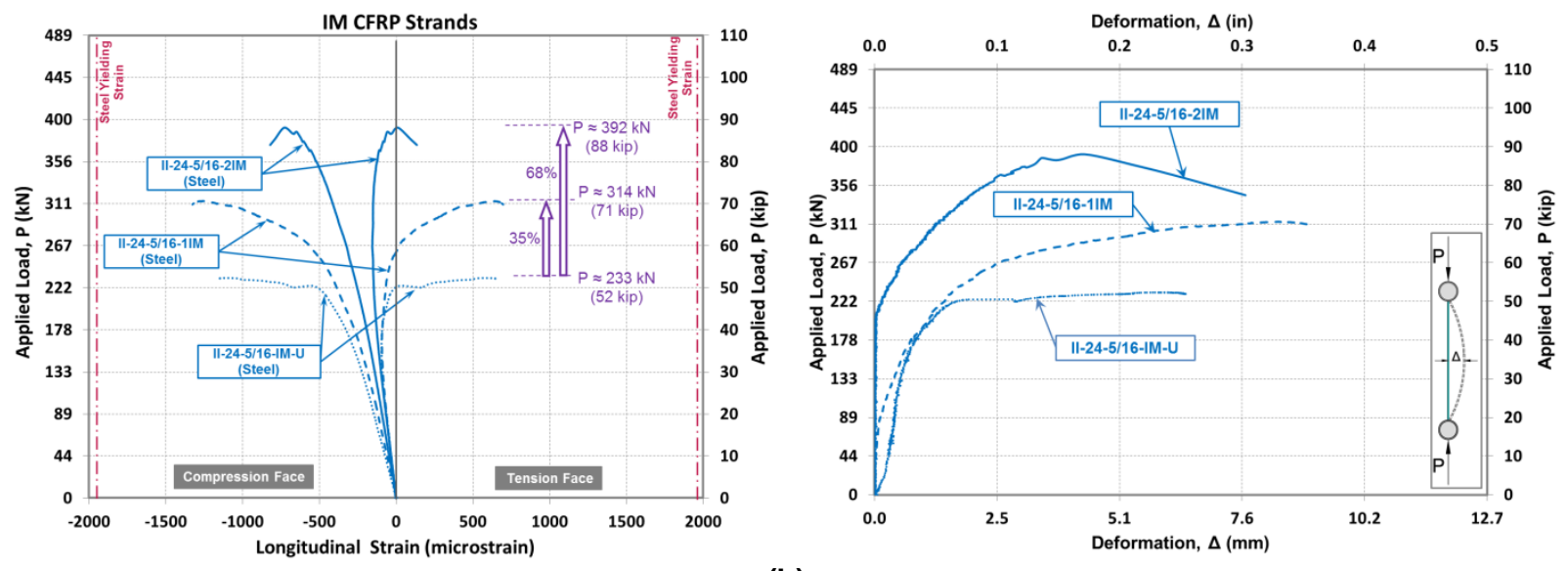

(b)
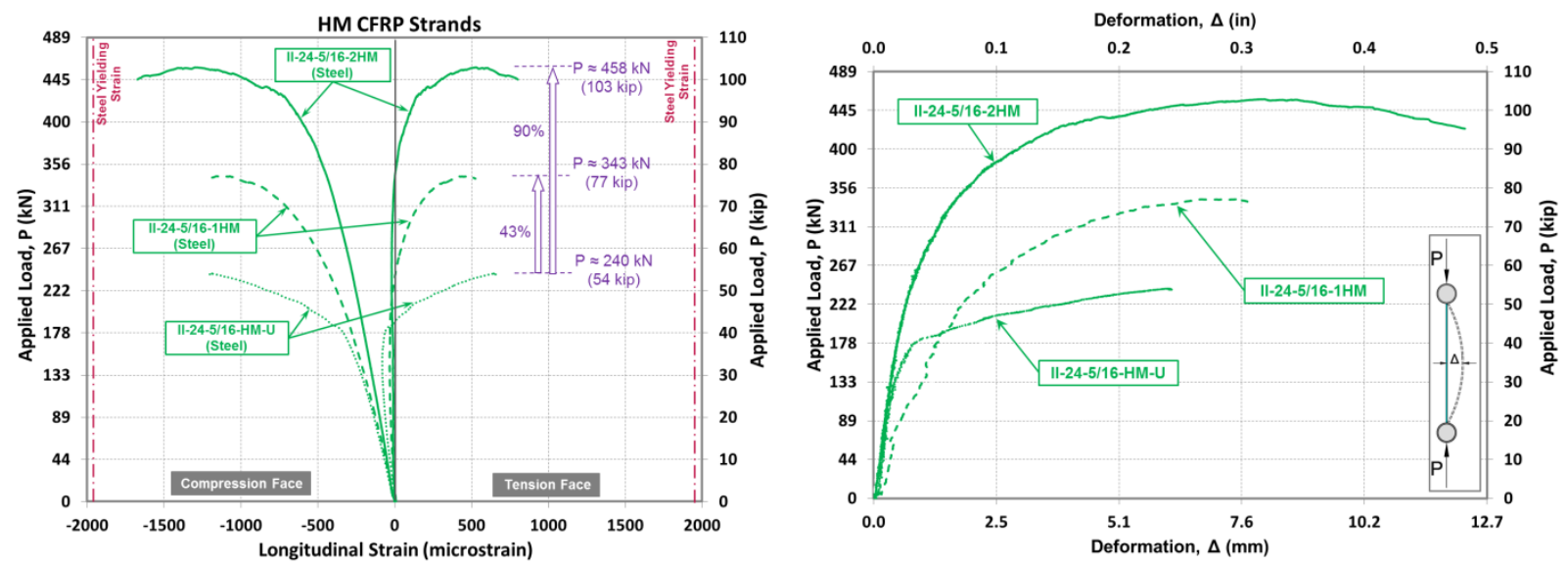

(c)

Figure 15: Applied load vs. longitudinal strain and net lateral deformation of the plates with slenderness ratio of 77 strengthened with, a) LM CFRP strands, b) IM CFRP strands, c) HM CFRP strands 

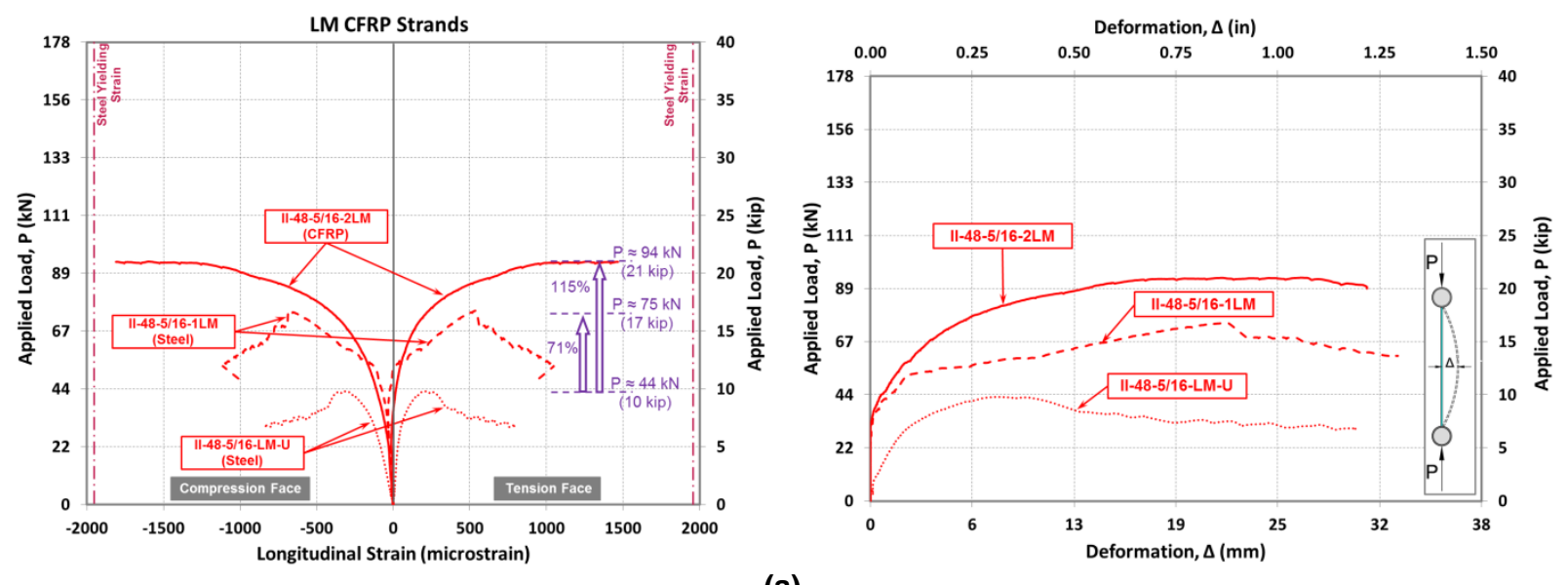

(a)
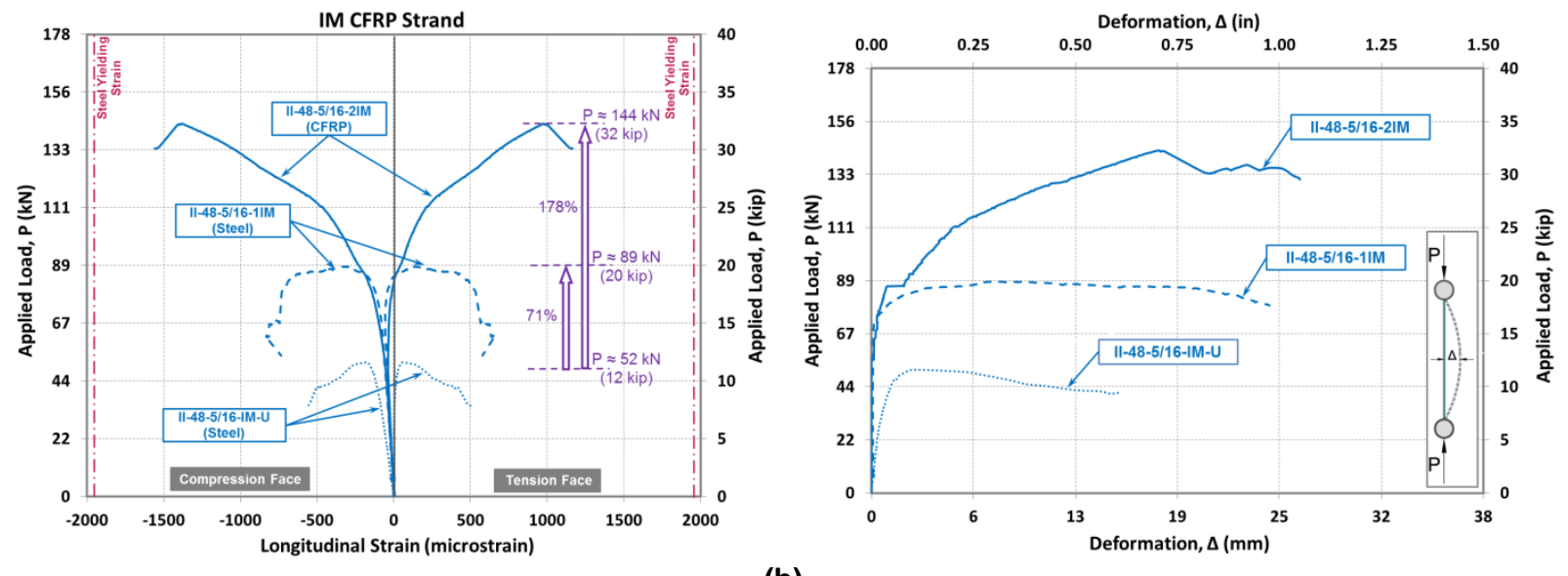

(b)
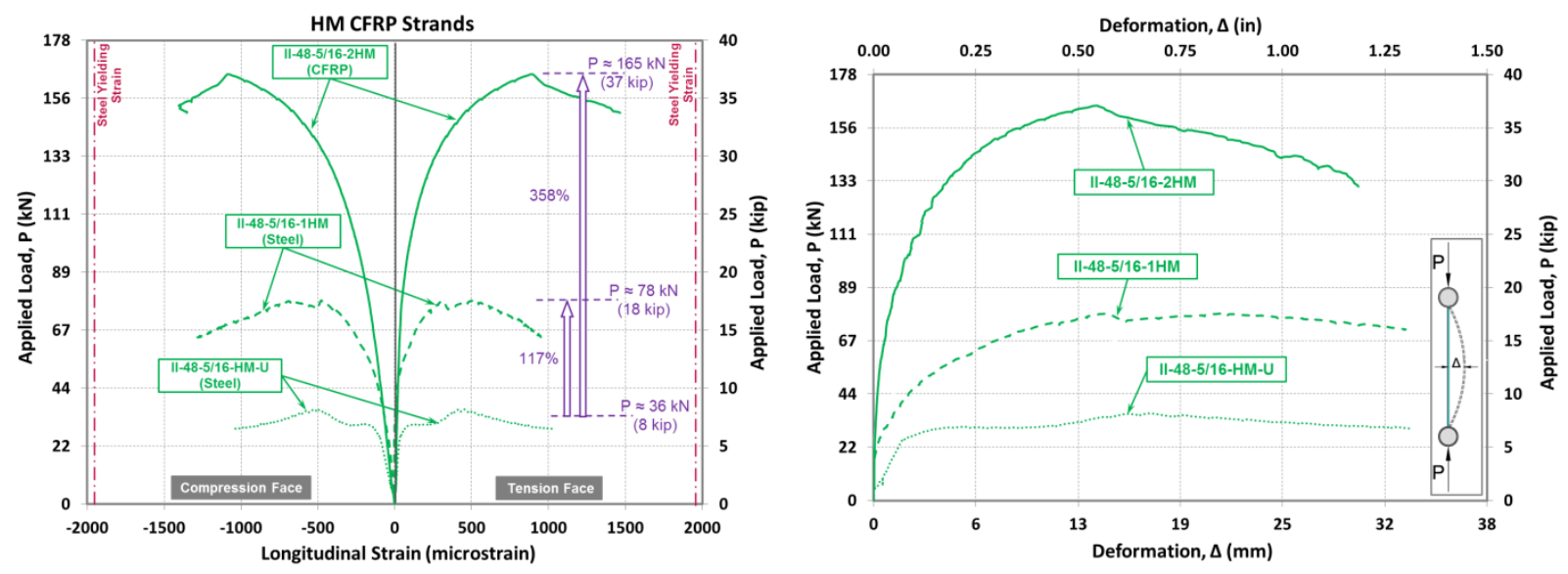

(c)

Figure 16: Applied load vs. longitudinal strain and net lateral deformation of the plates with slenderness ratio of 154 strengthened with, a) LM CFRP strands, b) IM CFRP strands, c) HM CFRP strands

9 Descending branch after the buckling is shown in Figure 17 for plates with slenderness ratio of 77 and strengthened with IM CFRP strands as a sample of all test plates. Results indicate that all plates 

and did not experience any residual strains.

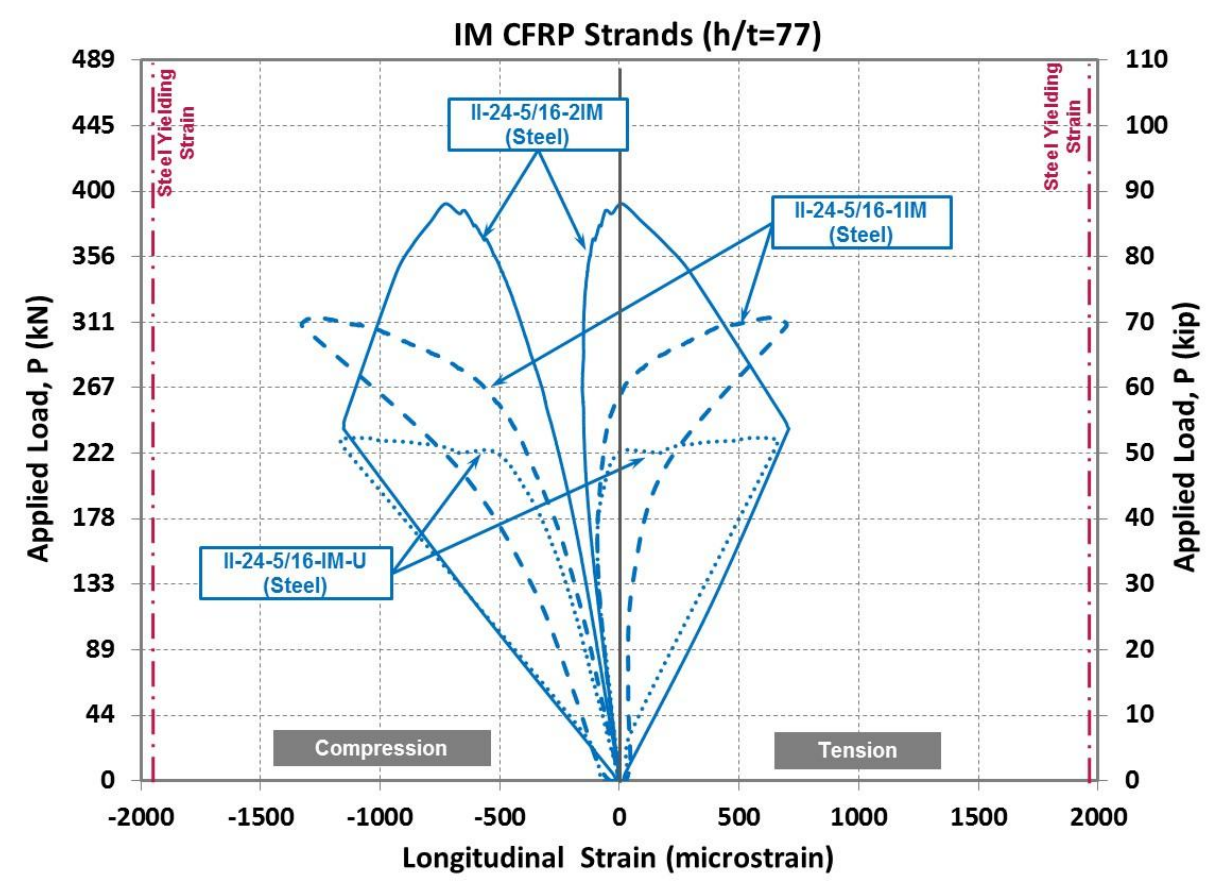

Figure 17: Applied load vs. Iongitudinal strain of the plates with slenderness ratio of 77 strengthened with IM CFRP strands followed by unloading branch

6 The increase of the buckling capacity of the specimens tested in Phase II is given in Figure 18. The

7 figure indicates that increasing the elastic modulus of the CFRP strands leads to a higher buckling capacity, since the buckling capacity is not governed by the rupture strength of the CFRP strands. The

9 figure also shows that the effectiveness of the proposed strengthening system increases as the 10 slenderness ratio of the steel plate increases. This behavior is attributed to the stiffness of the CFRP 11 strengthening system and becomes more effective for high slenderness ratio in comparison to the lower 12 ones. It should be noted that some inconsistency of the results may be due to the effects of the plate 13 imperfection. 


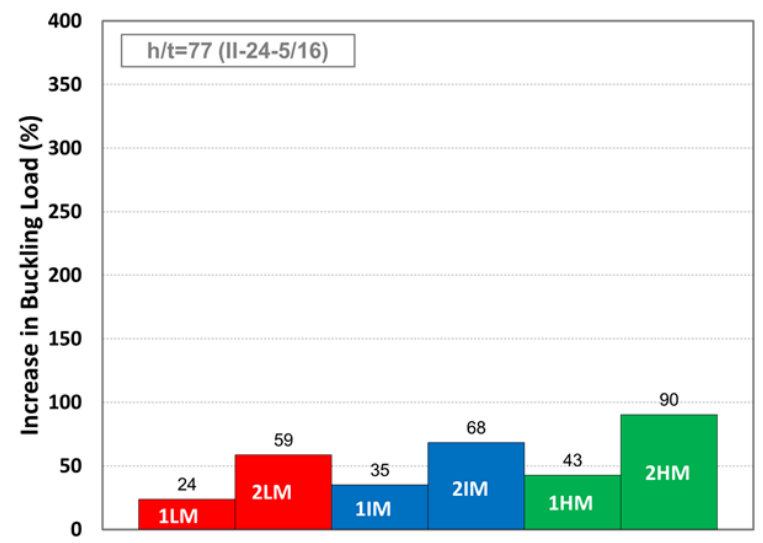

(a)

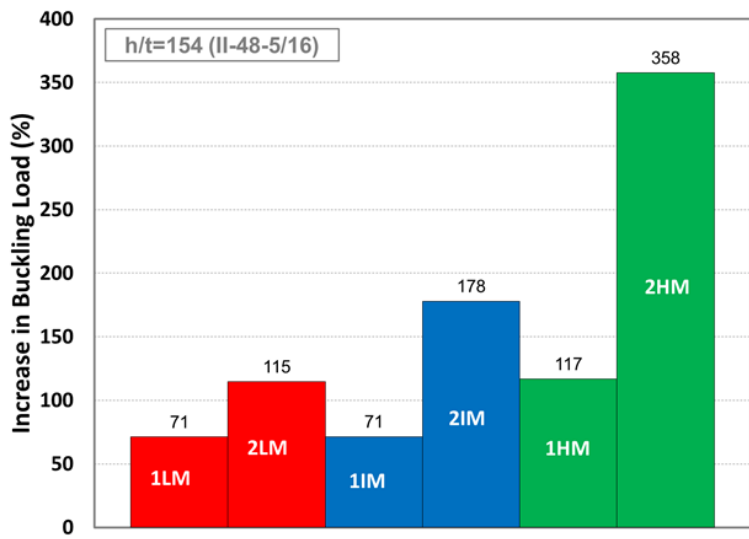

(b)

Figure 18: Buckling load percentage increase of plates strengthened with one and two layers of HM, IM, and LM CFRP strands, a) $h / t=77$, b) $h / t=154$

\section{4 \\ 6. Theoretical Buckling Prediction}

In this section, the theoretical buckling loads were determined using Euler buckling equations for steel columns. Since the steel and the CFRP strengthening system have different material properties, the transformed section method was used to determine the elastic buckling observed by the tested specimens. Use of the transferred section is due to the observed perfect bond of the strengthening system to the steel substrate. The buckling load, $P_{c r}$, for each tested specimen was estimated using following equations,

$11 \quad P_{c r}=\frac{\pi^{2} E_{S} I_{t}}{(K L)^{2}}$

where,

$14 \quad I_{t}=I_{s}+\sum_{i=1}^{n} \frac{E_{f i}}{E_{s}} I_{f i}$

$16 \mathrm{~K}$ is effective buckling length factor, $\mathrm{L}$ is the total height of the plate, $E_{s}$ and $E_{f i}$ are elastic modulus of steel

17 and the compressive elastic modulus of each CFRP layer, respectively. $\mathrm{I}_{\mathrm{t}}, \mathrm{I}_{\mathrm{s}}$, and $\mathrm{I}_{\mathrm{fi}}$ are moment of inertia of the transformed cross-section, moment of inertia of steel, and moment of inertia of each CFRP layer. 
1 Compressive elastic modulus of CFRP witness panels were used in calculations. Resembling hinge-hinge boundary condition used in the experimental program, the buckling length factor, $\mathrm{K}$, was set to one. The

3 predicted buckling loads are compared to the measured values for all tested specimen, including the 4 control and strengthened plates, as shown in Figure 19.

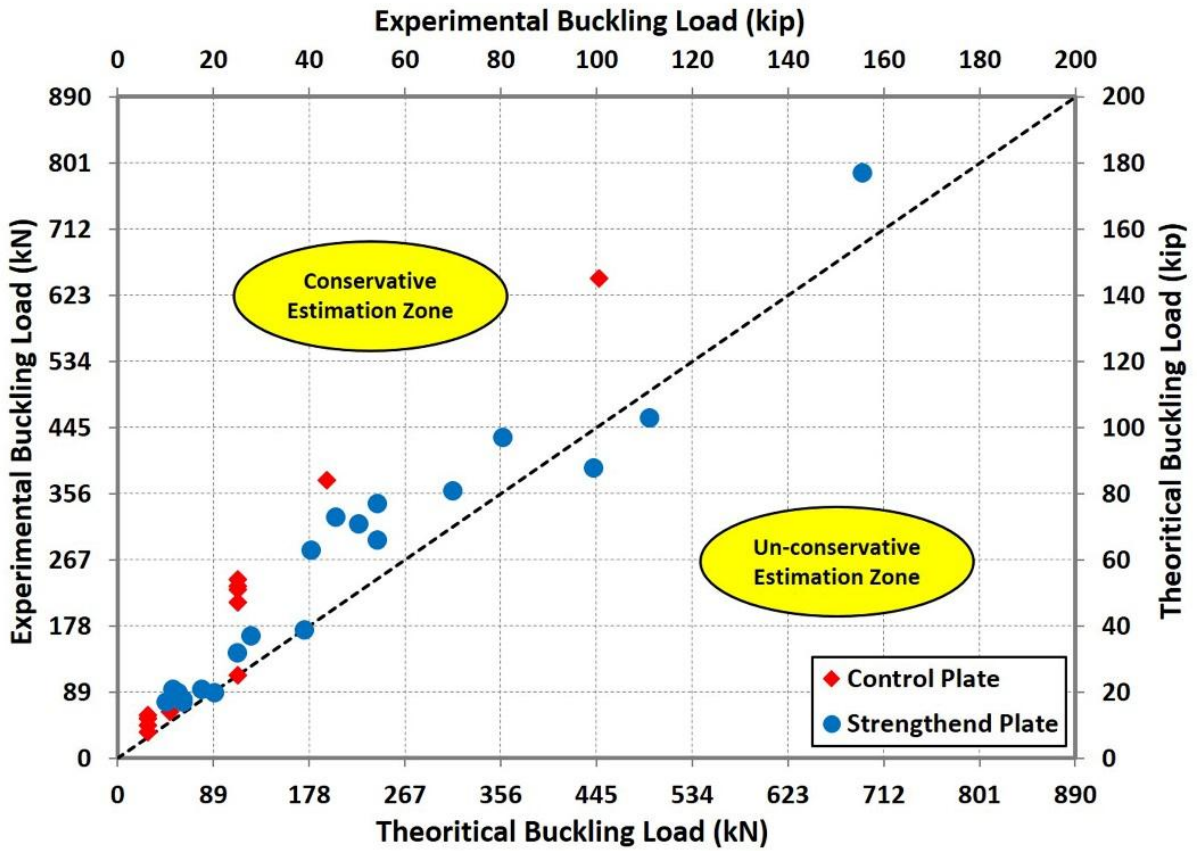

Figure 19: Comparison between measured and predicted buckling loads

The comparison shown in Figure 19 indicates that the buckling load can be adequately estimated using transformed section properties of the strengthened plate. The comparison should be improved by accounting for the friction between the pins and the sleeves which reduces the buckling length factor, $\mathrm{K}$, and consequently increase the predicted values. For the design, the above analysis indicates that the buckling capacity can be accurately predicted by using the proper boundary conditions and the composite transformed section properties of the strengthened steel plates.

\section{Summary \& Conclusion}

The study presented in this paper explores the use of small-diameter CFRP strands for strengthening of steel plates subjected to uniaxial compression. The study is part of a comprehensive research program to use the same material for shear strengthening of steel girders. In general, test results show that the 
small-diameter CFRP strands provided an excellent strengthening system for steel structures and eliminated any possible debonding of the strengthening material up to failure.

Based on the test results, the following conclusions can be drawn:

1. Small-diameter CFRP strands have proven to be an effective strengthening system for steel members subjected to compression.

2. The proposed strengthening system exhibits excellent bond characteristics in compression and in tension and eliminated any possible debonding up to failure.

3. The effectiveness of the small-diameter CFRP strengthening system increased by increasing the slenderness ratio of the plates and increasing the CFRP reinforcement ratio.

4. High modulus, small-diameter CFRP strands provide the best effective strengthening system in comparison to intermediate modulus and low modulus small-diameter CFRP strands used for plates subjected to compression.

5. Use of the proposed strengthening system increases the initial lateral stiffness of the strengthened plate.

6. Polyurea putty has no significant effect on the bond characteristics and the efficiency of the CFRP strands strengthening system.

7. Failure of the strengthened plates was due to elastic buckling, since buckling occurred prior to yielding of the steel or debonding of the CFRP strands.

8. Buckling equations can be used to estimate the buckling capacity of the strengthened specimens using the transformed cross-section properties.

The use of small-diameter CFRP strands is effective in enhancing the buckling capacity of steel plates and consequently believed to be a good potential for shear strengthening of steel girders.

\section{Acknowledgments}

4 The authors would like to acknowledge the contribution of the following parties for their support to this research: Nippon Steel \& Sumikin Material Co., Ltd, Composites Company, Japan for financial support, the National Science Foundation (NSF) Center of Integration of Composites into Infrastructure (CICl) at 
1 North Carolina State University, and SteelFab, Inc for donating the steel materials used in the research

2 program. Thanks are also due the staff of the Constructed Facilities Laboratory (CFL) at North Carolina

3 State University for their assistance throughout the experimental program, without whom this research

4 would have ever been possible.

\section{9. References}

1. Rahai A, Akbarpour H. Experimental investigation on rectangular RC columns strengthened with CFRP composites under axial load and biaxial bending. Composite Structures 2014; 108:538-546.

2. Teng $J$ G, Yu T, Fernando D. Strengthening of steel structures with fiber-reinforced polymer composites. Journal of Constructional Steel Research 2012; 78:131-143.

3. Zhao X, Zhang L. State-of-the-art review on FRP strengthened steel structures. Engineering Structures 2007; 29: 1808-1823.

4. Ghafoori E, Motavalli M. Innovative CFRP-Prestressing System for Strengthening Metallic Structures. Journal of Composites for Construction 2015; 19(6): 04015006.

5. Schnerch D, Dawood M, Rizkalla S, and Sumner E. Proposed design guidelines for strengthening of steel bridges with FRP materials. Construction and Building Materials 2007; 21:1001-1010.

6. Rizkalla S, Dawood M, Schnerch D. Development of a carbon fiber reinforced polymer system for strengthening steel structures. Journal of Composites Part B: Engineering 2008; 39: 388-397.

7. Schnerch D, Rizkalla S. Flexural strengthening of steel bridge with high modulus CFRP strips. Journal of Bridge Engineering (ASCE) 2008; 13:192-201.

8. Fam A, MacDougall C, Shaat A. Upgrading steel-concrete comosite girders and repair of damaged steel beams using bonded CFRP laminates. Thin-Walled Structures 2009; 47:1122-1135.

9. Tabrizi S, Kazem H, Rizkalla S, Kobayashi A. New small-diameter CFRP material for flexural strengthening of steel bridge girders. Journal of Construction and Building Materials 2015; 95:748756.

10. Sen R, Liby L, Mullins G. Strengthening steel bridge sections using CFRP laminates. Journal of 
Composites Part B: Engineering 2001; 32: 309-322.

11. Colombi P, Poggi C. An experimental, analytical and numerical study of the static behavior of steel beams reinforced by pultruded CFRP strips. Journal of Composites Part B: Engineering 2006; 37: 64-73.

12. Shaat A, Fam A. Axial loading tests on short and long hollow structural steel columns retrofitted using carbon fiber reinforced polymers. Canadian Journal of Civil Engineering 2006; 33:458-470.

13. Zhao X L, Fernando D, Al-Mahaidi R. CFRP strengthened RHS subjected to transverse end bearing force. Engineering Structures 2006; 28: 1555-1565.

14. Shaat A, Fam A. Slender steel columns strengthened using high-modulus CFRP plates for buckling control. Journal Of Composites For Construction 2009; 13:2-12.

15. Harries K A, Peck A J, Abraham E J. Enhancing stability of structural steel sections using FRP. Thin-Walled Structures 2009; 47:1092-1101.

16. Zhao X L, Al-Mahaidi R. Web buckling of lightsteel beams strengthened with CFRP subjected to end-bearing forces. Thin-Walled Structures 2009; 47:1029-1036.

17. Aguilera J, Fam A. Bonded FRP plates for strengthening rectangular hollow steel section t-joints against web buckling induced by transverse compression. Journal of Composites for Construction 2013; 17: 421-432.

18. Rizkalla S, Tadros G. A smart highway bridge in Canada. Concrete International 1994; 6: 42-44.

19. ASTM A370-12a. Standard Test Methods and Definitions for Mechanical Testing of Steel Products1. ASTM International, 2012.

20. ASTM D3039/D3039M-08. Standard test method for tensile properties of polymer matrix composite materials. ASTM International, 2008.

21. ACl 440.3R-04. Guide test methods for fiber-reinforced polymers (FRPs) for reinforcing or strengthening concrete structures. ACI Committee 440, 2004.

22. ASTM D66416641M-14. Standard Test Method for Compressive Properties of Polymer Matrix Composite Materials Using a Combined Loading Compression (CLC) Test Fixture. ASTM 
International, 2014.

23. Okuyama Y, Miyashita T, Ogata T, Fujino K, Ohgaki K, Hidekuma Y, Horimoto W, Nagai M. Mechanical Behavior of Plate Bonded FRP Sheets Under Uniaxial Compression Load. The Third Asia-Pacific Conference on FRP in Structures (APFIS), Hokkaido University, Japan, 2012.

24. Komori A, Kobayashi A, Hidekuma Y, Ohgaki K. Reinforcing method and reinforcing structure for steel structure and elastic layer forming material for reinforcing steel structure. US Patent: US 2013/0157060 A1, published date June 20, 2013.

25. Salmon C G, Johnson J E, Malhas F A. Steel structures design and behavior (Fifth edition). Pearson Prentice Hall, 2009.

26. VanDerNeut A. Post buckling behaviour of structures. V.T.H. REPORT 69: Technical University, Delft, 1956.

27. Alinia M M, Gheitasi A, Erfani S. Plastic shear buckling of unstiffened stocky plates. Journal of Constructional Steel Research 2009; 65: 1631-1643. 